Portland State University

PDXScholar

6-1-1966

\title{
Marital interaction theory: some implications for research
}

\author{
Lucille S. Pugh \\ Portland State University \\ John C. Douglas \\ Portland State University \\ Eleanor M. Gadway \\ Portland State University \\ Jeanna C. Greenlee \\ Portland State University \\ Margaret D. McGill \\ Portland State University
}

See next page for additional authors

Follow this and additional works at: https://pdxscholar.library.pdx.edu/open_access_etds Let us know how access to this document benefits you.

\section{Recommended Citation}

Pugh, Lucille S.; Douglas, John C.; Gadway, Eleanor M.; Greenlee, Jeanna C.; McGill, Margaret D.; Mackenzie, Beverly S.; Smith, Marjorie H.; and Smith, Violet S., "Marital interaction theory: some implications for research" (1966). Dissertations and Theses. Paper 505.

https://doi.org/10.15760/etd.505

This Thesis is brought to you for free and open access. It has been accepted for inclusion in Dissertations and Theses by an authorized administrator of PDXScholar. Please contact us if we can make this document more accessible: pdxscholar@pdx.edu. 


\section{Author}

Lucille S. Pugh, John C. Douglas, Eleanor M. Gadway, Jeanna C. Greenlee, Margaret D. McGill, Beverly S. Mackenzie, Marjorie H. Smith, and Violet S. Smith 
MARITAI INTERACTION THEORY:

SOME IMPIICATIONS FOR RESEARCH

\author{
by \\ Lucille S. Pugh \\ John C. Douglas \\ Margaret D. MoGill \\ Eleanor M. Gadway \\ Beverly S. Mackenzie \\ Jeanna C. Greenlee \\ Marjorie H. Smitin \\ Violet S. Smith \\ Project Director \\ James I. Breedlove, D.S.W.
}

A GROUP RESEARCH PROJECT

Presented to the School of Social Work

of Portland State College

in partial fulfillment

of the requirements for the degree of

Master of Social Work

June 1966

PORTLAND STATE COLLEGE

LIBRARY 
APPROVED :
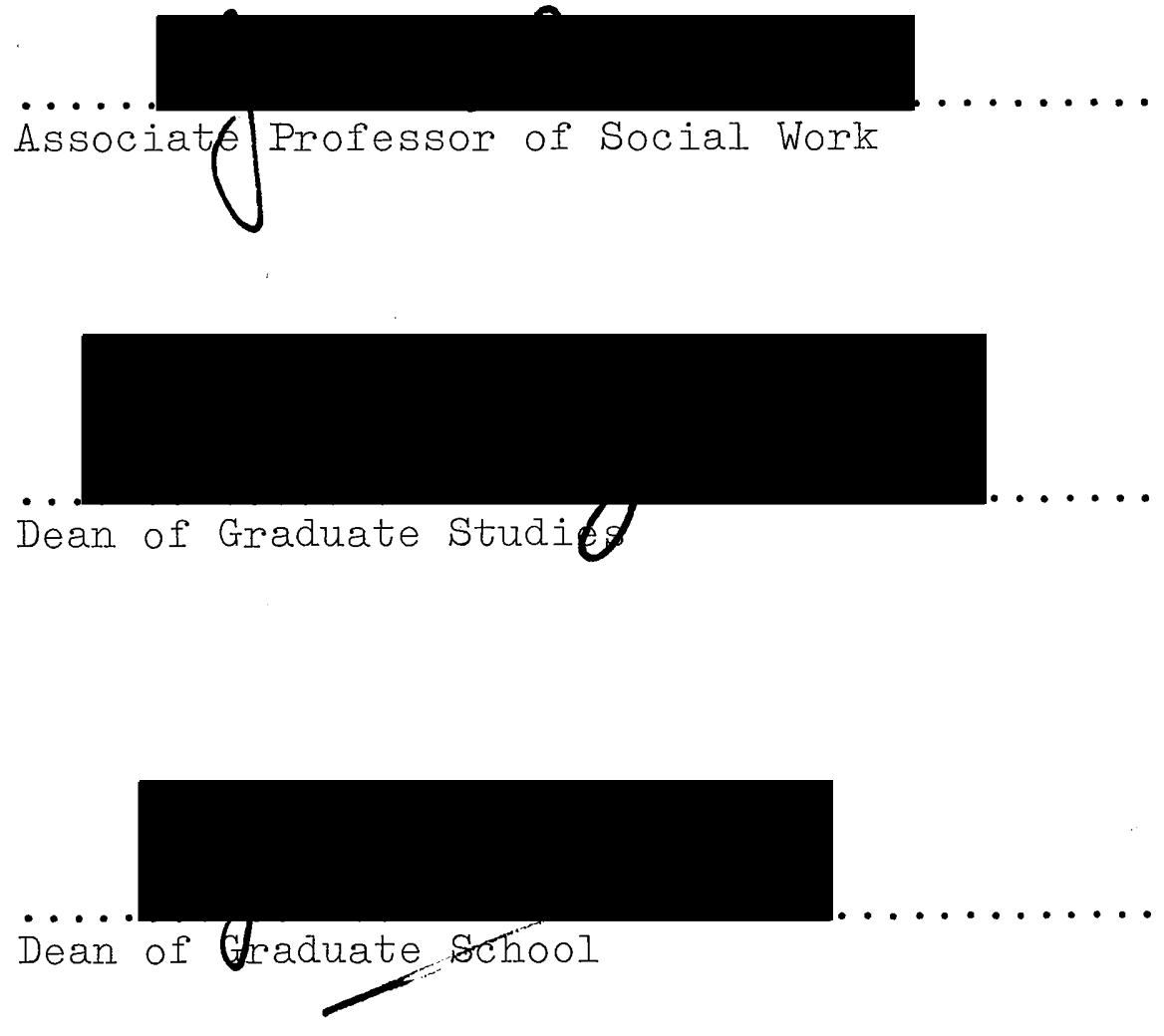

Date report is presented ... May. 9. $1966 \ldots \ldots \ldots \ldots \ldots \ldots$

Typed by Maud Alexander 
Pugh, Lucille et. al. (Name)

in

Social Work for the

Masters

(Degree)

Date thesis is presented

May 9, 1966

Title

Marital Interaction Theory:

Some Implications for Research

Abstract approved

$$
\text { Ryajor Professor) }
$$

This project examines specific basic areas of marital interaction theory. Individual chapters are developed around the following themes: historical development of the theory of interaction; a theoretical discussion of selected concepts; personality as a determinant of interaction; communication in marriage; marital interaction patterns; methodology pertaining to research findings; and finally some implications for research which became apparent as this project developed.

The project lays the conceptual groundwork for a series of empirical studies that will use the interactional approach as a theoretical base... The immediate purpose of this project therefore is to describe the important dimensions of the interactional approach as these pertain to marital interaction. Interaction is defined as a reciprocal relationship in which each person may produce effects upon the other. Here the essence of marriage is interaction; thus marital interaction is critical in its effect on the spouses and the continuity of the marriage.

Some of the basic concepts of George Mead are described and it is suggested that they are essential elements of the interactional approach. The major assumptions of this approach are that a) human behavior cannot be derived or inferred from nonhuman forms, b.) the social act is the primary analytic unit for an understanding of society and the personality, c) the human infant is potentially social, and d) the human bejng is actor as well as reactor. 
Personality is discussed as a determinant of the quality and quantity of marital interaction. The issue of personal competence is explored, particularly in respect to verbal ability. Communication, the process oi influence, is defined for marital interaction and the consequent formation of patterns.

Identification and classification of marital inter. action patterns are limited to a description of selected examples from family research and the observations of clinicians. Patterns tend to be defined in psychological terms although communicative behaviox is stressed. The absence of common criteria and terminology is noted. Description of dysfunctional patterns predominates.

Two methods frequently used in recent studies of marital interaction are direct observation and analysis of reports from marital partners. It is suggested that a combination of these techniques could increase the quantity of information about marital interaction.

Research questions focus on the problem of adult socialization, its implications for the establishment of marital interaction patterns, and the need to deterthe relation between the interaction process and the functional or dysfunctional quality of the resultant pattern. An inseparable part of the aforementioned. research areas is the function of communication. It is suggested that investigation of verbal. communication might yield significant data for the understanding of the interaction process as it affects the personalities of the spouses and the formation of patterns. 


\section{PREFACE}

This research project, entitled Marital Interaction Theory: Some Implications for Research, began as a review of recently published literature about marriage. Ihe International Index on Periodicals, The Cumulative Book Index, Psychological Abstracts, and Bibliographic Index. were searched for relevant material published between January, 1960 and March, 1965. As articles were reviewed, each source of theoretical orientation was identified by referring to the author's footnotes. In areas which seemed most meaningful, more intensive reading was undertaken and central ideas were traced back to their historic origins.

The theoretical framework of the interactional approach with its concentration on the act as the basic unit of obserm vation seemed to be the most useful way of looking at marriage for the profession of social work. This report provides a conceptual mapping of the important dimensions of this approach. It is designed as the first of an ongoing series of studies. This report does not attempt to extend theory but to describe a framework of existing theory for future empirical studies. 
TABLE OF CONTENTS

I. Introduction ...................... I

The Significance of the Interactional

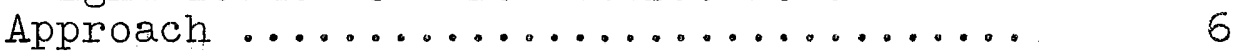

Historical Development of the Interactional

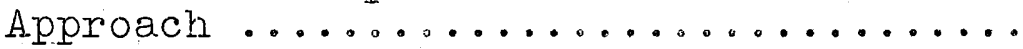

Relative Advantages of the Interactional

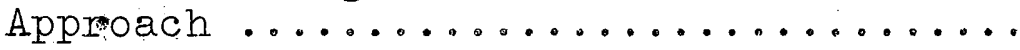

II. The Interactional Approach to the Study of

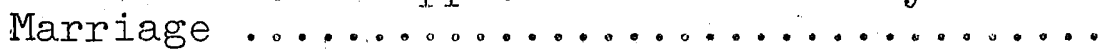

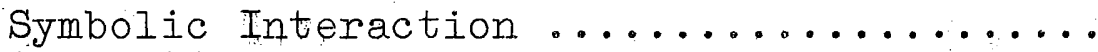

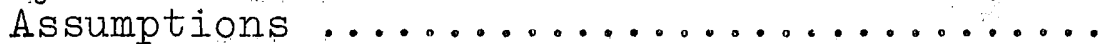

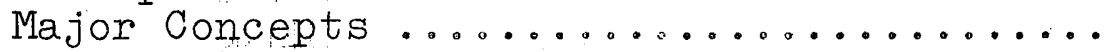

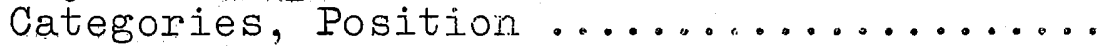

Role, Self, Development of Self ..........

Role-Taking, Generalized Other, Significant Other and Role Conflict ............

Which Concepts are Useful as a Way of Understanding Marriage? .............

II. Personality as a Major Determinant in Marital

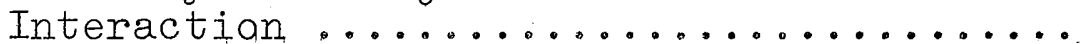

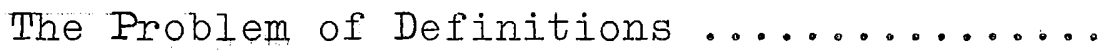

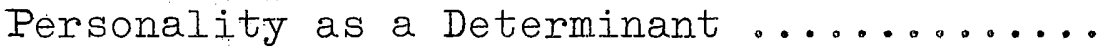

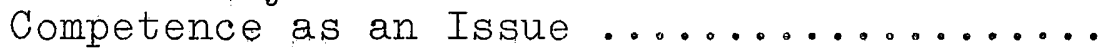
Summary

IV. Communication in Marriage ............... 42

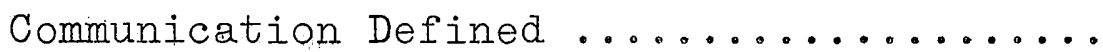

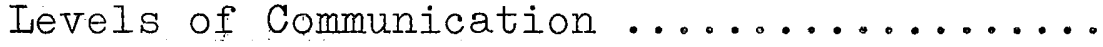

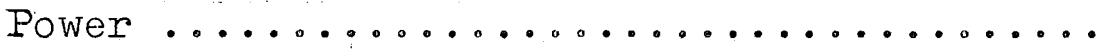

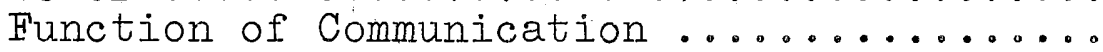

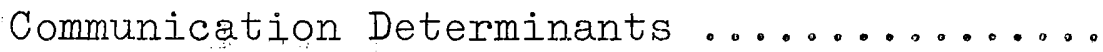

Communication Patterns: Some Revelant

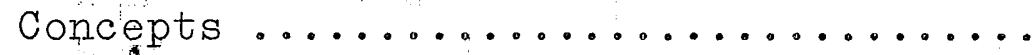

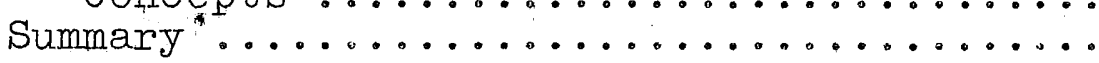


V. Marital Interaction Patterns ............. 64

Early Recognition of Behavior Patterns .... 64

Framework for Understanding Interaction

Patterns ...................... 67

Marital Interaction Patterns ........... 70

Determinants of Disturbance in Marriage.... 71

Ehrenwald's Patterns ............... 73

Mittleman's Neurotic Complementary

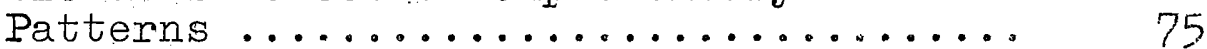

"Marital Schism" and "Marital Skew" ....... 76

Berne's 'Games' ................... ${ }^{76}$

Haley's Communicative Behavior Patterns ... 77

Some Comments on Patterns ............ 78

Summary ....................... 81

VI. Some Measurement Issues for Marital Interaction

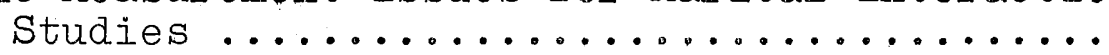

Problems of Measurement .............. 83

Direct Measurement of Marital Interaction • 84

Indirect Measurement of Marital

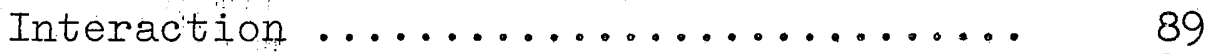

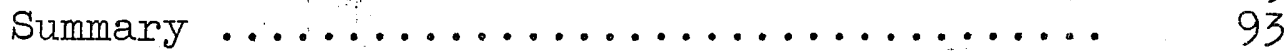

VII. Some Implications for Research ........... 95

The Problem of Definitions ................. 96

The Problem of Socialization ............ 97

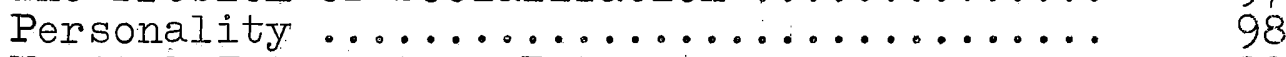

Marital Interaction Patterns ............ 99

Communication .................... 100

Conclusion .................... 101

Biblitography $\ldots \ldots \ldots \ldots \ldots \ldots \ldots \ldots \ldots \ldots \ldots \ldots$

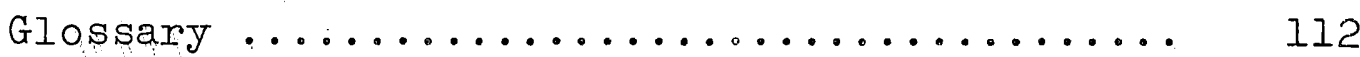


MARITAI INTERACTION THEORY :

SOME IMPIICATIONS FOR RESEARCH

\section{CHAPTER I}

\section{INTRODUCTION}

The purpose of this project is to review the interactional approach to the study of marriage. The project first reviews the historical background of the interactional approach. Present day interactional concepts have emerged by means of an evolutionary process, as found in the writings of Plato and other early philosophers, then later found in the works of the social psychologists of this century, and eventually in the works of present day clinicians. The project presents a general review of a specific approach. It is not a review of issues, nor is it evaluative: it is descriptive, with some attempt to assess how this approach can be useful in social work research. The project is designed as the first phase in an ongoing series, and as such, it develops a conceptial mapping of the important dimensions of this interactional approach to the study of marriage. The project examines basic areas of marital interaction theory. Individual chapters are developed as follows: historical development of the theory of interaction; a theoretical discussion of selected concepts; personality as a determinant of interaction; 
communication as a factor in marriage; marriage interactional patterns; methodology pertaining to research findings; and finally, some implications for research which became apparent as the project developed.

The link between the individual and society as a whole is the basic social unit known as the family. If social workers are to serve individuals effectively, they must be well aware of the family as a system of interacting personalities. It is one of the purposes of this report to contribute to this awareness, which should lead, in turn, to further study and research in closely related areas and be of diagnostic value in the broad area of social work.

The feasibility of viewing the family as an interacting unity was suggested by Ernest Burgess forty years ago. Burgess had been studying the patterns of personal relationships in family life, and his study in that area led to his concept of the family as "a unity of interacting persons" (Burgess, 1926, p. 5). It was Burgess' contention that the actual unity of family life should not be defined in legal terms, but rather, in terms of the interaction of its members. Burgess believed, then, that the very essence of marriage is the interaction, and the family lives as long as interaction is taking place.

The concept 'interactional' as used in this report is exemplified by Sampson (1964): 
As a concept, interaction denotes the formation of a relationship between two or more persons, $A$ and $B$, such that $A^{\prime} s$ behavior serves both as a stimulus for B and as a response to B's behavior which in turn may serve as both a stimulus and a response for A. Interaction, therefore, involves a reciprocal relationship in which each person may produce effects on the other $(p, 51)$.

In addition to the interactional approach there are four other approaches to the study of marriage and the family: (1) the structural-functional, (2) the situational, (3) the institutional, (4) the developmental. These approaches differ considerably in emphasis, although similarities between them are readily discernible.

The interactional approach emphasizes the significance of personality determinants as these determinants influence each human being's tendencies, or potentialities, for action. This approach focuses on the family of interacting persons, and it concerns itself with process. Overt behavior is primarily considered in terms of specific interacts. Role analysis is of major importance, and this framework has also focused on such problems as status relations (which leads to authority patterns), processes of communication, conflict, decisionmaking, and, in general, the continuum of interactive processes from courtship to the divorce court (Hill and Hansen, 1960). 
The structural-functional approach views the family as a social system with emphasis on maintenance of the family system and, ultimately, of the social system (Hill and Hansen, 1960). Family structure is oriented toward boundary maintenance of the system, and behavior is studied in the context of its contribution to this maintenance. This approach is extremely versatile, as it really copes with three broad areas:

(1) the interaction of the individual family member with other individuals, and subsystems in the family with the full family system;

(2) the interplay of subsystems with other subsystems and with the full family system; and

(3) the transaction of the family with outside agencies and other systems in society, and with society (the social system) itself (Hill and Hansen, 1960, p. 304).

The situational approach focuses on the situation itself, or the individual's overt behavior in response to the situation. The family is seen as a unit of stimuli acting toward a focal point (a child, for example). However, the framework allows not only for analysis of the behavion of that focal point in the family situation, but also allows for study of the situation itself (Hill and Hansen, 1960).

The institutional approach emphasizes the family as 
a social unit in which the individual and cultural values are of central concern, and it deals best with social change and family development over long spans of time. It is concerned with transactions of the family institution with other social or cultural structures, and only in highly generalized fashion does it deal with interaction as a process. The family institution is often referred to as the most important of institutions (Hill and Hansen, 1960).

The developmental approach involves the concept of stages of a family life cycle, with developmental needs and tasks. It is concerned with the life cycle of the nuclear family, and emphasizes the ever-changing internal structure and development of the family over time. Like the interactional approach, the developmental approach views the family as a unity of interacting personalities, intricately organized internally into certain paired positions ( such as wife-mother, daughter-sister). This small group has a predictable natural history designated by logical stages, progressing from the simple husband-wife pair to the successively more complex stages as additional positions are activated, then to the less complex as members depart from the group, and it contracts to the husband-wife pair again. The family changes as its member composition -. and their ages -- change. At the same time the quality and type of the interaction also changes (Hill and Hansen, 1960). 
The Significance of the Interactional Approach

Interactional theory is a product of social psychology, and as such, addresses itself first of all to what Stryker (1959) refers to as 'socialization': "how the human organism acquires the ways of behaving, the values, norms and attitudes of the social units of which he is a part" (p. 1ll). The focus, then, is not on any static state, but on an on-going process which involves the human organism and its ever changing social environment.

Along with socialization, interactional theory addresses itself to personality, which stryker (1959) defines as "the organization of persistent behavior patterns" ( $\mathrm{p} .112)$. Personality is considered in some detail in Chapter III.

Highly significant in the interactional approach is the fact that within this approach personal organization and personal disorganization are treated as different aspects of the same problem. From this position, answers to both can be provided without calling upon principles which lie outside of the theoretical scheme of this approach.

Historical Development of the Interactional Approach

Although the interactional approach to the study of marriage is recognized today as a direct outgrowth of 
the work of George Herbert Mead and a group of University of Chicago interactionists, its roots may be Iocated in the very gradual development of social thought, beginning with the writings of Plato. Plato early emphasized that man must be understood in his social environment rather than as an isolated individual. He stressed his belief that not only did man effect changes in his environment, but also, he himself was subject to change by environmental influences (Plato, 1937).

These writings constituted the first suggestion of man as a really social being interacting with his fellow man and with his environment. From that first suggestion, the idea in one form or another was presented from time to time. It was Aristotle, pupil of Plato, who introduced a comparative method of studying social institutions, not only demonstrating their relative value but also demonstrating that, in order to meet changing social conditions and social needs, institutions themselves must change, and their change would in turn effect some modification of man's behavior (Aristotle, 1900).

These were the expressed early beginnings of interest and concern for man as a social being. In the middle of the nineteenth century more ideas were recorded in the literature that appear to be additional precursors to modern interactional theory. Gabriel Tarde developed. ideas in this area into a sociological theory, centered 
around the process of imitation as practiced by man in adjust-w ing to his fellow man and to his environment. He stressed three processes: repetition, opposition, and adaptation. According to Tarde (1903) all social phenomena can, ultimately, be reduced to the relation between two persons, one of whom exerts influence ppon the other.

At approximately the same time Tarde was developing his theories in France, Georg Simmel in Germany was becoming concerned with a different phase of interaction, Simmel's sociological thought begins with the process of social becoming. After a study of the descriptive data of history in search of generalizations, it was his contention that the social process in which man involves himself first of all springs out of social interaction. Simmel (1950) defined 'socialization' as "the growing into a unity" (p. 10). To Simmel, sociology was essentially the science of socialization, or of the forms of unity within which people live.

In the evolutionary process which led eventually to current interactional theory the next man of importance was Charles Horton Cooley who made vital' contributions to the field of social psychology, of which the interactional theory is a part. It was Cooley who formulated the concept of The Looking Glass Self (Cooley, 1922). This concept was derived from the assumption that even a person's consciousness of himself is largely a direct 
reflection of the opinions which he believes others hold about him (Cooley, 1922).

A contemporary of Cooley, George Herbert Mead, also contributed to sociological understanding about communication, language, the consciousness of meaning, and the meaning of self. Mead (1924) believed that each personality is definitely affected by contact with other personalities, and that an individual plays as many different roles as there are other individuals to whom he responds. According to Mead's theory of self, the self includes the ego, or 'I', which is an active agent, or activity itself. Self also includes an empirical self, or 'me', which is constructed out of one's experiences in the social environment.

Mead's work led directly to the interactional approach as it is known today, although a workable description of the conceptual framework seemed to be lacking until Hill and Hansen (1960) published their work. They present the family as a unity of interacting individuals,

\footnotetext{
- . each occupying a position(s) within the family to which a number of roles are assigned, i.e., the individual perceives norms or role expectations held individually or collectively by other family members for his attributes and behavior. In a given situation, an individual. defines these role expectations
} 
primarily in view of thejr source (reference group) and bf his own seff-correption. Then he role-plays. Most immediately the family is studied through analysis of overt interacts (interaction of roleplaying family members) cast in this structure (p. 302).

\section{ReIative Advantages of the Interactionat Approach}

Historically social psychologists have disagreed about what Stryker (1959) terms "some metaphysical priority of society over the individual" (p. 112). Some maintain that society itself is the ultimate reality, while others place emphasis and importance on the individual. Either position, however, results in ambigulity. By beginning its analysis with the social act itself, interactional theory by-passes the disagreement. Interaction is its basic unit of observation, and it is from interaction that both society and the individual derive (Stryker, 1959).

This formulation allows a kind of communication between soclology and social psychology that is not readily available to the other four alternative frameworks mentioned previously. Both sociology and social psychology begin with social actions. From this beginning, sociology goes toward "the behavior of collectivities" (Stryker, 1959, p. 112) while psychology, from the same base, goes toward the behavior of 
individuals. Those who attempt to study the family find that the problems involved bridge these two fields, and in the interactional approach they are provided a framework "facilitating movement from one level to the other, allowing systematj.c transactions between the two levels" (Stryker, 1959, p. 112).

Since the interactional approach assumes the family to be a relatively closed system of interaction, it is narrower in scope than the structure-function approach, and some of the broad and rich ideas that emanate from the structure-function approach are missing. The interactional approach may be thought of as a microscopic approach. This is viewed by some as a severe disadvantage. Zimmerman, for example, disdainfully refers to the interactional approach as a study of the "mechanics of marriage" rather than a true family study (Zimmerman, 1935). Others pnefer to view the family in terms of macroscopic changes of the institutional features, or within large cultural or societal contexts. These people, too, are unhappy with the interactional approach.

From the point of view of social work, however, the interactional approach, viewing marriage, as it does, as a constant socialization process, provides a unique opportunity to look at individuals in their immediate context: as members of a constantly changing system of interacting personalities. 
As the chapters in this report are presented, timey approximate a frame of reference, with discussion of the major concepts involved. One of the reasons for this organization was the hope that the report might constitute a guide for future students who may wish to work in the general area of marital interaction. 
CHAPTER II

\section{THE INTERACTIONAI APPROACH \\ TO THE STUDY OF MARRIAGE}

There are, perhaps, as many definitions of the wora 'theory' as there are theorists. 'Theory' can be taken to mean a set of concepts which sensitizes one to certain aspects of behavior or a set of laws which describe certain phenomena. There are partial theories and there are "grand theories" such as one finds in some laws of physics which can explain most laws as well as most phenomena (Zetterberg, 1963). According to Hearn (1958), theory is an internally consistent body of verified hypotheses, the assumption being that verification is provisional rather than absolute.

Theory is important in any field because it explains phenomena. Concepts, the elements of theory, define what is to be observed. However, it is only when concepts are integrated into a logical scheme that theory emerges. If one is to study marriage from the interactional approach, to test the usefulness of the approach for understanding the complexities of marriage, a framework is necessary (Hill and Hansen, 1960).

Since the interactionist approach has not been developed into a systematic theory of marriage, this chapter will review previous efforts to define and study symbolic interaction, to review the fundamental 
assumptions underlying the interactional approach and to assess which concepts may be useful as a way of understanding marriage, especially for the social worker.

\section{Symbolic Interaction}

The interactionist approach, according to Hill and Hansen (1960), was first developed in sociology and social. psychology. The approach was an outgrowth of the work of George Herbert Mead and the University of Chicago group of symbolic interactionists.

According to English and English (1958) social psychology is that branch of psychology which studies the phenomena of social behavior, especially as it interacts with the personal characteristics of individuals. They point out that social psychology is actually a hybrid discipline that inherits from both parents (psychology and sociology) concepts, data, and problems.

Before looking at what various authors have to say about interaction and symbolic interaction, the words 'interaction, 'transaction', and 'symbolic interaction' will be defined as they are used in this report.

A close relationship exists between the words 'transaction' and 'interaction' and there also exists some tendency to use them interchangeably. 'Transaction' is taken to mean a process which includes a two-phase, 
cyclical exchange between two individuals in which there is constant feedback which is largely self-regulating and self-correcting and which modifies the subsequent response of each individual (Dewey and Bentley, 1949). 'Interaction' implies the action of one person and the response of another (Weiss and Monroe, 1959).

Individuals in responding to one another may be involved in what Mead referred to as a "conversation of gestures". Of this Stryker (1959) states:

- b they come to use early stages of
another's acts as indicators of later
stages. Such gestures have meaning.
Vocal sounds can seem as gestures and
they too have meaning. This meaning of
a gesture (an early stage of an act) is
the behavior that follows it (the later
stages of the act): meaning is, by
definition, behavior. Some gestures have
an additional property. They may mean
the same thing, imply the same set of
subsequent behavior, to the organism which
produces this gesture and that which per-
ceives it. When this occurs, the gesture
becomes a significant symbol. . .
Ianguage, basically, is a system of
significant symbols. . . (p. liz).

'Symbolic interaction' means that symbols (a word or gesture that stands for something else) in communication (the concept of communication includes all those symbolic processes by which people influence one another) (Reusch and Bateson, 1951) are significant symbols or gestures. According to Mead this means that: 
- the individual must know what he is about; he himself, and not merely those who respond to him, must be able to interpret the meaning of his own gesture. Behavioristically, this is to say that the biological individual must be able to call out in himself the response his gesture calls out in the other, and then utilize this response of the other for control of his further conduct. Such gestures are significant symbols. . . (p. 27).

The calling out of the same response in both gives the necessary common content for communjty of meaning.

It is through interaction that symbols are invented. Language, a mode of interaction, involves at least two beings, a speaker and a hearer and it presupposes that both belong to an organized group from which they have acquired their habits of speech (Duncan, '1962).

Conventional interaction theories are derived from the assumption that action occurring between persons is reciprocal. The unit of action is the person. According to Sarbin (1954), the general formula is that when A initiates an action to $B$, B's response to $A$ serves as a stimulus for $A$ and so on.

Following this formula of interaction (which all. sociological theories seem to imply implicitly or explicitly), in a marital action when a wife, for example, asks her husband a question, his response to her serves as a stimulus for her and hers for him and so on. But there is certainly more involved than simple responses. 
How does each respond and why? How does each see himself? How does each see the other? What goes into the response? These are some of the questions which interaction theorists seek to answer.

Stryker (1959) indicates that as a social psychological theory, symbolic interaction is concerned first with the question of socialization, that is, how the organism acquires ways of behaving: the values, norms and attitudes of the social units of which he is a part. Here, the focus is on the development of what happens to the human over time. Second, symbolic interaction is concerned with personality. Here the focus is on the organization of persistent behavior patterns.

Kantor (1964) explains that symbolic interaction implies that people act with reference to each other. Each fits his conduct to the conduct of others by checking what they are doing or what they mean to do. Each builds up his own behavior on the basis of interpretations of the behavior of others. Group action occurs through the mutual tailoring of individual lines of action. Such tailoring assumes that there are predictable forms of social interaction which makes social relationships possible.

Regardless of whose interpretation one accepts or refers to, it is important to define the words used by interactionists as precisely as possible. Since the 
interactional approach borrows, so to speak, from many disciplines, the vocabulary is colorful and sometimes confusing. In the process of presenting the assumptions and concepts of the theory terms will be clarified and defined, at least as they are used in the context of this project. Among those which will be defined, are socialization, personality, communication, symbols, the act, the social act, category, position, role, self, role-taking, generalized other, significant other, role conflict,thinking, volition, and self-consciousness.

However, before proceeding with the assumptions and concepts it might be well at this point to state that the participants of this project are in agreement with Mead's position as a social psychologist. While Mead's own position is "behavioristic," it is a social behaviorism (that is, that behavior is influenced by the behavior of other persons) and not an individualistic behaviorism (Mead, 1934). Mead's is not the position of the psychological behaviorist, who, by preference, studies learning and motivation in a non-social environment.

According to Morris (Mead, 1934), Mead answered the problem as how the human mind and self arise in the process of conduct in bisocial terms.

Mead avoided the extremes of both the traditional psychologist and social scientist by an appeal to an 
ongoing social process of interacting biological organisms within which mind and self arise through the juternalization of the conversation of gestures in the form of the verbal gesture.

English and English (1958) point out that the term mind ". . has such a battered history that it can hardy be used clearly in technical writing. ." (p. 328). They list five definitions for the word and it is the first definition which is most appropriate for this project. It states that the mind is ". . . organized totality or system of all mental processes or psychic activities, usually of an individual organism . . " (p. 323). They state that the emphasis is upon relatedness of the phenomena; that mind in this sense does not commit one to a metaphysical position above the nature of these processes and this definition may be used by those who define psychology in terms of acts or: behaviors; but is more congenial to those who recognize a category of processes such as feelings and cognitions, which though related to behavior are still distinct.

Morris goes on to say that the individual act is seen within the social act, that psychology and sociology are united on a biological basis, and social psychology is grounded in social behaviorism. It is in these terms that Mead's theory bridges the gap between impulse and rationa... ity, by showing how certain biological organisms acquire 
the capacity of self-consciousness, of abstract reasoning, of thinking, of purposive behavior; in other words he shows how man arose from an impulsive to a rational animal.

Mead believes that the human cortex and the temporal dimension of the nervous system (which provides the control of the gesture in terms of the consequences of making it) permits the human animal alone to pass from the level of the conversation of gestures to that of the significant language symbol and it is the absence of the first which "prevent the talking birds from talking . . ." (p. xxiii).

\section{Assumptions}

All theory must have assumptions, that is to say, judgments which one accepts as if true, in a train of reasoning, though they have not been proved. Stryker (1959) lists four assumptions upon which symbolic interaction is based.

(1) The initial assumption is that man must be studied at his own level. Symbolic interactionists take the position that valid principles of human sociaj psychological behavior cannot be derived or inferred from the study of non-human forms. According to stryker (1959), this assertion rests on the principle of emergence. Hemergence suggests the existence of qualitative differences as well as quantitative continuities 
among the precipitates of the evolutionary process" (p. 112).

If man is qualitatively different from other animal forms, in some respects, it follows that principles derived from other forms cannot completely account for his behavior.

(2) A second assumption is that symbolic interaction begins its analysis of society with the social act. Inter-m action is its basic unit of observation and from that action both society and the self derive.

(3) A third assumption concerns the newborn infant. The assumption here is that the human infant enters life neither social nor antisocial but with potentialities for social development.

For purposes of this project, this assumption is expanded to include the following: The infant enters life with potentialities for development of personality or self. By personality is meant "The thinking, feeling, acting human being who for the most part conceives himself as an individual separate from other individuals and objects. This human does not have a personality; he is a personality" (Witmer and Kotinsky, 1952, p. 3).

Personality consists of attitudes, ideas, and habits of the individual. The concept iraplies that within a 
person tendencies to act, or predispositions, exist prior to and after the overt responses to which they give rise. Such tendencies are designated as attitudes. Personality refers to these tendencies in interaction with one another. Although it is implied that personality develops through learning and experience, the importance of biologically inherited traits and characteristics is not denied.

(4) A last assumption is that the human being is an actor as well as a reactor. The assumption that the buman being does not simply' respond to stimuli occurring outside himself leads to what Stryker (1959) refers to as the fundamental principle of symbolic interaction: ". . the demand that the investigator see the world from the point of view of the subject of his investigation" (p. 112).

\section{Major Concepts:}

An assumption of the theory is emergence and the principal emergent at the human level is language behavior.

The starting point is with the act. The act is behavior by an organism which stems from an impulse requiring some adjustment to relevant objects in an external world. In a social act, the appropriate object is another individual. Social acts involve at least two individuals acting with reference to each other. Since acts occur over 
time they have a history. This makes possible the appearance of gestures, defined as "any part of the act which stands for, or comes to be a sign of, those parts of the act jet to occur" (Stryker, 1959, p. 113).

\section{Categories, Pösition}

Some symbols, called categories, represent generalizations of behavior toward objects. To apply a class term to a number of objects or to signify that for certain purposes, different things are to be treated as the same kind of thing is to categorize (Stryker, 1959): Classification is necessary because life would be too confusing if one had to respond to every object as unique. Categories are symbols. They have meaning, are cues for, and help organize behavior. According to Stryker (1959), "Humans respond to a classified world, one whose salient features are named and placed into categories indicating their significance for behavior" (p. 114).

An important kind of category is one called 'position'. Gross, Mason and McEachern (1958) use the term 'position' to refer to the "location of an actor or class of actors in a system of social relationships" (p. 48). Positions are then socially recognized categories of actors serving to classify persons such as father, wife, paramour, and so on. 
Such categories are significant since they serve to organize behavior toward categorized persons. By attaching a position designation to a person one is led to expect certain behavior from him and in turn behave toward him on the basis of these expectations (Stryker, 1959). Indeed, one cannot retain one's identity unless it is validated by others.

\section{Role, Self, Development of Self}

According to Stryker (1959), "To the expectations with regard to behavior attached to a position the term 'role' is given" ( $p$. 114). In evaluating the definition of role used by various authors, including Linton who as an anthropologist stressed cultural patterns, Gross, Mason and McEachern (1958) came to the conclusion that most definitions of role are derived from the assumption that individuals behave with reference to expectations.

Under certain circumstances an actor may respond to himself as he responds to other people, by naming, defining and classifying himself. To engage in this kind of behavior is, according to Stryker (1959), to have a self. He believes it is useful to define the self in terms of categories one applies to himself, as a set of identifications.

Mead (1934) defines 'self' as 


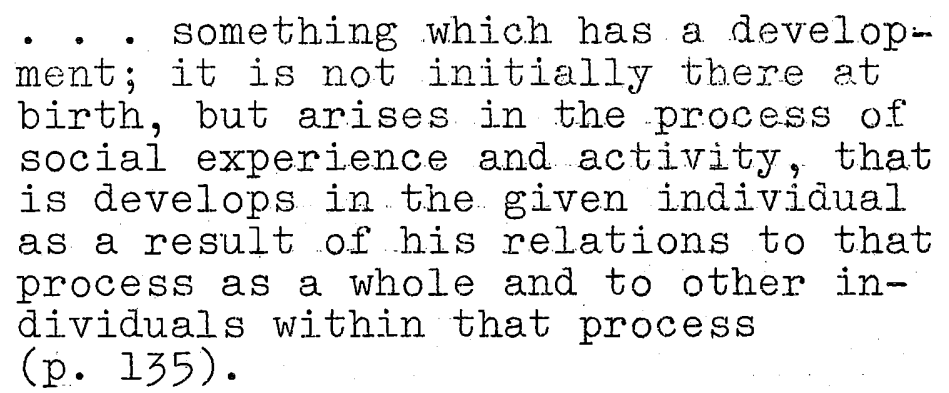

He stresses that self is that which arises as an object. That is to say, that as one becomes aware of himself as an object with specific characteristics, he develops selfconsciousness. Because he is conscious of himself, he can reflect on his experiences and control his own actions.

Role-Taking, Generalized Other, Significant Other and Role Conflict

Mead stresses two stages in the development of the self, those of play and the game. In play the child assumes one role after another, of persons and animals too, that have in some way entered his life. In this way, he assumes the attitudes of others through role-taking or taking the role of the other.

Stryker (1959) defines role taking as "anticipating the responses of others implicated with one in the same social act" ( $\mathrm{p} \cdot 115)$. Role-taking may involve the anticipation of some particular other, that is to see one's behavior as taking place in the context of a defined system of related roles (Stryker, 1959). 
Mead stressed that role-taking develops in playing of the game. In the game, he pointed out that one "becomes" all of the others involved in the common activity in order to successfully play one's own part. Here the person does not merely assume the role of a specific other (as in play) but of any other participating in the activity.' In this way he has generalized the attitude of role-taking and taken the attitude or role of the "generalized other."

The concept of the "significant other" is also used. in symbolic interaction theory. This concept recognizes that not all persons with whom one interacts have identical or even compatible perspectives. In order to proceed, therefore, the individual must give greater priority to the: perspectives of particular others. In other words, certain others occupy high rank on a continuum of importance for any given individual (Stryker, 1959).

It has been pointed out that the concept of self is developed as the child interacts with others and moves from one social situation to another. In the socialization process, the individual learns how to view and evaluate his behavior and act with reference to himself as well as to others (Stryker, 1959).

The individual occupies, concurrently and through time and at the same time, a variety of positions in sets 
of social relationships. He can do so because there is continuity and organization among the behaviors of a given individual (Stryker, 1959).

If meanings are shared with those persons with whom one interacts, congruence (harmony or agreement) is likely. When meanings are diverse among those with whom one interacts, incongruities in expectations as well as personal disorganization may result (Stryker, 1959).

Parsons (1951) defines incongruities in expectations as a role conflict. He states, "By role conflict is meant the exposure of the actor to conflicting sets of legitimized role expectations such that complete fulfillment of both is realistically impossible" ( $p .280)$. Parsons went on to say that in order to resolve role conflict it may be necessary to compromise, to sacrifice some of both sets of expectations, to choose an alternative and sacrifice the other or to redefine the conflict.

Bateson (1961) proposed a classification of interactions called 'double binds' in which there is confused expectation. Usually an interaction will proceed according to the expectation or label that has been placed upon it. Double binds occur when a preceding contextual label disagrees with the eventuality (Bateson).

A last set of concepts is what stryker (1.959) describes as the "unashamed use" symbolic interaction 
makes of mental concepts such as thinking, volition and self-consciousness. These terms are defined operationally. The internalized manipulation of language symbols is cate-gorized as thinking. The process of selecting among alternatives symbolically presented becomes volition. And, the activity of viewing oneself from the standpoint of others is called self-consciousness.

\section{Which Concepts are Useful for Understanding Marriage?}

This chapter is based on the belief that the interactional approach is a useful way of looking at and understanding marriage. It was stated in the introduction that concepts are elements of theory, they define what is to be observed but only when they are integrated into a logical scheme are they meaningful. Now that the concepts have been set forth, how useful are they?

Using the model Hill and Hansen (1960) developed in an interactional approach in family study, an interactional conception of marriage could take these lines: The marriage is a unit of two interacting individuals each occupying a marital position(s) within the marriage to which a number of roles are assigned. That is, the individual perceives norms or role expectations held by the other as well as by himself for his attributes and 
behavior. In a given situation, the individual defines these role expectations primarily in view of their source (reference groups--this includes generalized others and significant others) and of his own self-conception. Then he role plays, that is, he performs or enacts the role. The marriage is studied through analysis of overt interacts (interaction of role playing) cast in the marital structure.

The approach focuses on role and on such problems as position and interposition relations, which become the basis for authority patterns and initiative taking. Every position assumes some counterposition just as every role presumes some counter-role. For example, one cannot talk about the behavion of husband without reference to the position of the wife and so on. The approach also focuses on processes of communication, conflict, problem-solving, decision making and stress reaction; and other aspects of marital interaction from dating to divorce or death.

of special significance for the social worker is that marriage offers a unique opportunity to study continuing socialization processes and personality with which symbolic interaction is primarily concerned. 


\section{Summary}

This chapter reviews previous efforts to explicate symbolic interaction, defines some of the words used by symbolic interactionists, reviews the fundamental assumptions underlying the interactional approach and points out what in the concepts is useful as a way of conceptualizing and understanding marriage. 
CHAPTER III

\section{PERSONALITY AS A MA.JOR DETERMINANT}

IN MARITAL INLERACIION

The purpose of this chapter is first to describe the concept of personality as it has been used in the interactional approach to the study of marriage. The term personality will be defined in relation to Mead's theory and the social psychological approach as represented by Stryker, Burgess, Miyamoto, and Dornbusch. Second, personality will be examined as a component of marital interaction. It is suggested that personality is a major determinant in marital interaction and competence in marital interaction involves a person's capacity for response to the other. The focus will be on the social aspects of the personality since it is not within the scope of this chapter to do more than delineate some basic issues in determining the effect of personality on marital interaction. Interaction as used here refers to the reciprocal activity between two persons, hence, it is not possible to comprehend the action fully without some knowledge of the persons. Personality is an essential concern in the interactional approach. 
The Problem of Definitions

Personality as a term has suffered much of the same abuse as other words whose meaning varies with context, tone of voice, and referent. Although 'personality' in popular usage can denote a quality such as sex appeal, here the basic denotation will be the persistent attitudes or predispositions of an individual.

In order to understand the term personality from the interactional point of view, it is necessary to restate Mead's approach to the person as seen in the development of the concept 'self'. Mead (1934) treats the self as the result of the social experiences of the: individual and adheres to the argument of the impossibility of a person developing a self without an accumulation and integration of social experiences. He further states that,

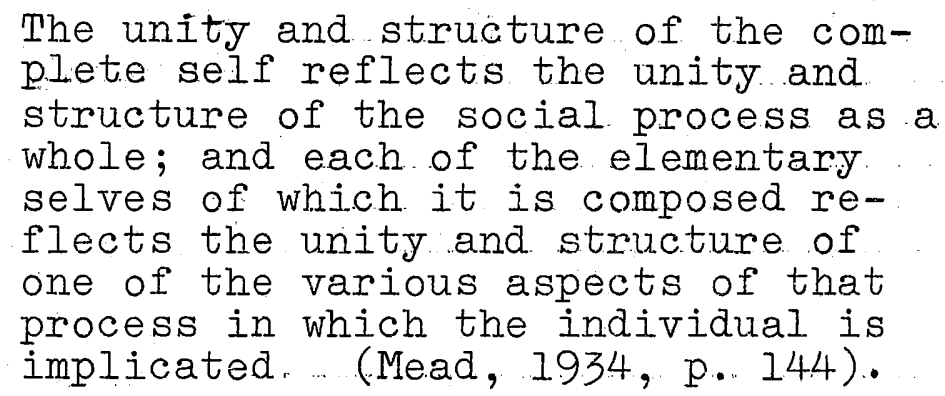

In other words, Mead defines the self as the introjection by the person of various social experiences which in turn become an object not only for the person 
but for others. The self is an organtzation of attitudes of individuals and groups; Mead implies that personality arises as this organization becomes defined.

Although Mead uses personality as synonomous with the total organized self, it is necessary to point out that he emphasizes the cognitive aspect of self. He eliminates habits and affective qualities from consideration as part of the self but leaves an opening for their return by the use of the 'I' which becomes the initiator, the actor, and the responder. The ' $I$ ' is the original innovating, unpredictable quality of the person that exists only in the present, since the moment the 'I' acts it has passed into the 'me' or the objective self. The 'I' is the vitalizing agent and the 'me' is the structure. "Taken together they constitute a personality as it appears in social experience" (Mead, 1934, p. 178).

The philosophy of George Mead continues to influence the interactional approach but it is not often made explicit. Burgess' (1926) discussion with its emphasis on the unity of interacting personalities, implies the self as he presents the social image as the basic reality for study. The social image is defined as the conception of one's role, which is the social reality of the personality. The unity of interacting personalities in the family is 
reminiscent of Mead's approach to the social process as a unity.

Stryker (1959) focuses on personality as one of two major concerns facing the interactionists. The other is socialization. His recognition of personality as an organization of persistent behavior patterns is consistent with Mead and Burgess. However, he challenges the social psychologist to account for the existence of this organization and its relationship to social processes. In attempting to define the self, stryker struggles with the "I" and "me" concepts of Mead and settles for a combination of reflexive activity and a set of identifications.

In an early paper Miyamoto and Dornbusch (1956) emphasize the influence of others' responses on the self. Their findings serve to develop the interactional approach to the personality and to indicate the complexity and importance of self-conception in interaction. They found that the relevance of the attitude of the other to self-conception increases the more the response of the other was incorporrated into the organization of the self. The actual response of the other was found to be less important than the subject's perception of that response or his opinion of the attitude of others toward him.

Personality as used in the interactional approach Is significant for social process. It is an organized 
structure which has resulted from interaction with others. Personality is the developed psychological organization of the individual that includes his attitudes, ideas, and habits. Personality determines the individual's capacity for response, and is expressed in consistent behavior patterns.

\section{Personality as a Determinant}

Personality is an integral part of marital interaction. Its structure serves to set limits on the interaction. In Levinger's (1965) terminology marital cohesiveness is the product of the positive attractions within the marriage, the barriers to its dissolution, and the absence of attractions from other sources. When barriers dissolve and extramarital attractions become more accessible, the cohesiveness of a marriage depends on the strength of attraction within the relationship. Personality is a major source of attraction, and it is through skill in the interactional process that the attraction is maintained. The inability of one spouse to interact positively within the limits of his own and his spouse's personality affects the cohesiveness of the marriage. In the United States two persons generally marry because of a personal attraction to each other and expect to find some satisfaction through the other's ability to provide for 
personal needs. Pincus (1960) stresses the relevance of self-fulfillment to satisfaction in marriage and states that self-fulfillment involves the expression of the personality of each partner. Others agree by noting that the structure and stability of the family depend upon the interrelationship of the personalities of the husband and wife (Lidz, 1963) (Rapoport and Rapoport, 1965).

Social psychological analysis accepts personality as expressed in patterned responses and is concerned with its totality. Mowrer and Mowrer (1961) state that the personality of the spouse as a unity through time determines, by its convergence with the personality of the marital partner, the success or failure of the marriage. The fact that specific traits are not considered as significant as the personality as a whole again reflects the interactional view of the self.

Personality contributes to the structure of the marriage. Just as the unity of the self reflects the whole social experience so does the social experience partake of the personalities of the actors. Hess and Handel (1959) state that the "structure of a family includes the intrapsychic organization of its individual members" ( .3$)$.

Using the personality-interaction approach, Huntington (1958) specified that the marital relationship contains three elements. These were (a) the interaction 
of the partners which included expressed needs, (b) the needs aroused but inhibited, and, (c) the defenses used to inhibit needs. He recognizes the complexity of interaction but states that interaction is more easily understood through a study of the personalities of the interactors. The use of his concepts permits a description of marital relationships and a way of analyzing the inter-action aș it occurs.

\section{Competence as an Issue}

Since personality plays such an integral part in interaction it is difficult to separate one from the other. Nevertheless, the qualitative and quantitative aspects of each are important to consider. In childhood the interaction greatly influences the development of the individual personality. In marriage, however, the personality is a well-defined unity that greatly influences the interaction. It may be hypothesized that how the spouses respond in marital interaction determines the degree of effectiveness of the interaction as a means of personal satisfaction.

In this report competence in marriage is the ability to meet one's own needs as well as those of one's spouse. Foote and Cottrell (1955) describe six components of interpersonal competence: health, intelligence, empathy, autonomy, judgment and creativity. Their discussion focuses on these components as capacities and abilities of the 
person essential for effective interaction. They continue by defining these six components as a more complete delineation of Mead's concepts with inteliigence, empathy and judgment corresponding to 'me' and health, autonomy, creativity, corresponding to 'I'.

The emphasis on the components as capacities and. abilities requires some attention to the developmental aspects of competence. If Foote and Cottrell are consistent with Mead then capacities and abilities would change through the interaction process as the self responded to the influence of the other. For example, the intelligence component includes the capacity to symbolize experience and to be articulate in communication. Although the personality of the adult is more defined than that of the child, change continues to occur through interaction. In this instance a positive change would be increased skill in the use of words.

Some recent studies have examined competence as it occurs in the use of language. These are useful additions to the interactional approach, since verbal communication is a significant component of interaction. In a paper describing the concept of verbal accessibility, Polansky (1965) linked verbal accessibility to the social situation and the personality. His findings indicate that verbal accessibility is relatively stable for individuals 
over time even though wide variations in verbal accessibility are found by content and social situation. Thus, verbal accessibility emerges as an important aspect of the personality. In marital interaction verbal accessibility, as an enduring part of the personality assocjated with the use of symbols, has an essential function. Failure of one or the other of the partners to express adequately his feelings or attitudes could contribute to a more general failure in the marital interaction. Competence in this area would appear to be critical for the marriage.

Moreover, the adequacy of expression of feelings and attitudes to the other is based on the predisposition of the person for self-disclosure. Jourard and Lasakow (1958) define self-disclosure as "the process of making the self known to other persons" (p. 91). Their findings indicate that married persons focus self-disclosure on the spouse. Since the amount of self-disclosure varies among males, females, and individuals, differences in selfdisclosure between spouses is apt to occur. Significant unresolved differences between the marital partners could also inhibit the effectiveness of the marital interaction. Although verbal accessibility remains relatively stable, development does occur in the use and understanding of symbols. Vygotsky's (1962) thesis is that woro meanings develop over time. Using data from experimental 
studies he presents a conception of the relationship of thought to word that stresses process.

The relation of thought to word is not a thing but a process, a continual movement back and forth from thought to word and from word to thought. In that process the relation of thought to word undergoes changes which themselves may be regarded as development in the functional sense (p. I25).

Vygotsky's thesis poses an interesting question for marital interactionists. If word meanings do develop in such a manner, how significant are discrepancies between the spouses in this development for effective interaction?

The ability to use words is critical to the personality not only in the expression of the self but also in the development of the self. Inadequacies in the use of words would seem to limit the individual's capacity for response to the other by limiting his understanding of the full sense of the other's symbols. A person whose word meanings had undergone limited development would not comprehend the richness of the more fully developed symbol of the other.

\section{Summary}

The interactional approach has been concerned with personality as a major part in the interaction process since the philosophical development of the concept 'self' 
by George Mead. In the study of the family, social psychologists have continued to emphasize and further define the meaning of personality, its structure and function, in interactional terms. The overall unity of the personality and the resultant pattern's of behavior are more pertinent to this approach than particular traits. The ideas of Mead are implicit in these later definitions. Since personality determines and is determined by social interaction, interpersonal competence emerges as a central issue in marital interaction. Foote and Cottrell's categories of health, intelligence, empathy, autonomy, judgment and creativity emerge as capacities integral to effective interaction. More useful to the symbolic interactionist, however, are hypotheses about the use of language and its impact on the success or failure of the interaction process as conceptualized by Polansky and Vygotsky. 
CHAPTER IV

\section{COMIUNICATION IN MAKR IAGE}

This chapter reviews the concept of communication in marriage as presented in recent research literature. First, the various definitions of communication and the definition accepted by this project as a basis for development are reviewed. The concept of power as it is related to communication in the marital relationship is discussea.. Finally the determinants of communication, functions of communication, and the patterns of communication are presented.

Communication Defined

Although communication ". - as a subject for contemplation has a history almost as long as that of writing" (Birdwhistell, 1962, p. 194), it has been a focus for scientific research, with a few notable exceptions, since just before World War II. There has been a steady increase of interest in communication in several fields including those of marriage and family research, social work, and psychotherapy. Various disciplines, including sociology, psychology, and social psychology, have studied communication. Many definitions and theories have developed. Thayer (1963) discusses the problems of theory building around the concept of communication pointing out that in a 
recent six year period more than 25 ". . conceptually different referants", ( $p$. 219) had been offered for this term. In 1961 Cherry wrote

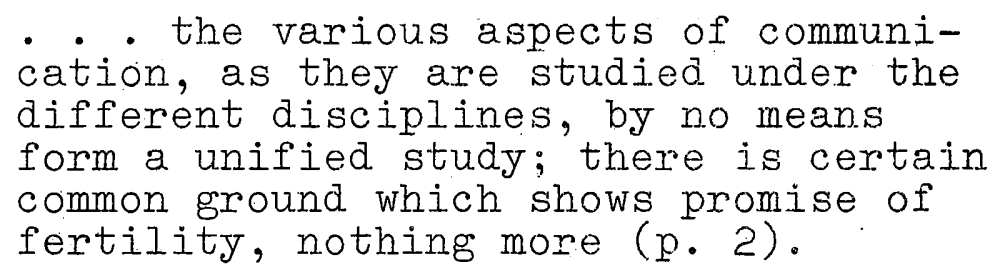

The definitions of communication reported in this chapter represent only a token sample and reveal considerable conceptual differences. These definitions are offered as a first step toward analyzing the importance of communication in the marital relationship, the primary concern of this chapter.

Cherry (1961) described communication as ". . essentially a social affair" (p. 3), and offered a broad definition as

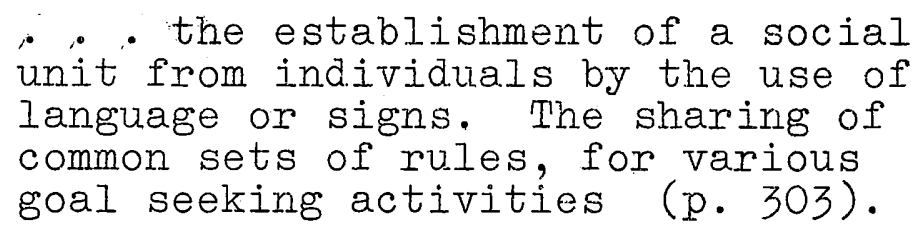

Blau and Scott (1962) have linked interaction and communication to

to different aspects of them. The
concept of social interaction focuses
principally upon the formal. character-
istics of social relation: such terms 


\begin{abstract}
as frequency, initiative, superordination, and reciprocity indicates its dimensions. The concept of communication... directs attention to the meaningful content conveyed in the encounter, and its characteristics are described by such terms as flow of messages, obstacles, positive and negative reactions, and exchange (p. 336).
\end{abstract}

Homans (1950) points out that the " . . word communication is neither general enough in one sense nor specific enough in another" (p. 37). People tend to think of communias a process taking place only through words. Homans includes both verbal and nonverbal communication under interaction. He states that communication

- may mean the content of the
message, signal or 'communication'
being transmitted, or the process
of transmission itself, as when
people speak of 'methods of com-
munication', or to the sheer fact,
aside from content or process of
transmission, that one person has
communicated with another (p. 37).

Schachter (1960) succintly defines the term:

". . communication, the process of one person talking to another, as the mechanism of induction, i.e., the means by which influence is exerted" (p. 275).

Virginia Satir (1964) indicates that communication "can mean interaction or transaction" and that it generally refers to both verbal and nonverbal behavior within 
a social context. "Communication also includes all those symbols and clues used by persons in giving and receiving meaning" (p. 63).

Verbal, nonverbal, and a combination of both are modes of communication throughout life (Ehrenwald, 1963, c). Communication can be viewed as a " . . dynamic process in a totally integrated individual with expressive activity observable in his overt behavior" (Barbara, 1963, p. 166). Communication can be healthy or not. "People are always in the process of communication---speaking, gestures, how we move, how we dress, a sense of touch, and all those other ways of expressing one's self" (Barbara, 1963, p. 167).

Mead (1934) made some important observations about communication. He pointed out that ideal communication occurs when "the individual would affect himself as he affects otherș in every way" ( $p .327$ ).

Bonner (1953) expressed a similar thought when he stated that communication is more than the transmission of abstract ideas but is also ". . . the act of putting oneself in the place of another person's attitude, where in the symbol that affects another affects the individual himself in the same manner" (p. 69).

Karlsson (1963) in speaking specifically of communication in marriage states that this is not primarily one of 
transmission of symbols but ". . . rather a problem of transmitting in some cases certain items of information, namely characteristics of role-expectations, intentions, feelings of love and respect, etc., and in other cases not transmitting them" ( $\mathrm{p} .38$ ).

Ruesch and Bateson (1951), whose definition of communication is referred to in Chapter II, state

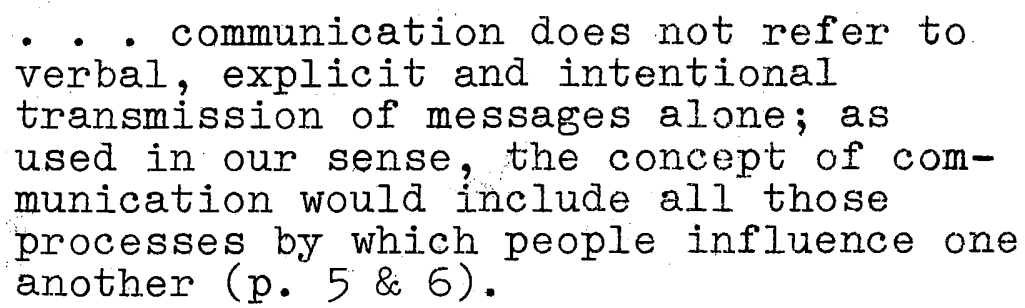

Communication has been described in broad as well as narrow concepts. It has been used by some interchangeably with interaction. It has been described as the content of the message or signal being transmitted. Communication has also been described as ". . . the act of putting oneself in the place of another person's attitude" so that ". . the symbol that affects another affects the individual himself and in the same manner" (Bonner, 1953, p. 69). For the purpose of this writing, Ruesch and Bateson's definition of communication will be used. Within this framework, communication will be described as a single act. For example, when $A$ makes a statement to $B$, the process produces change in $A$ and in $B$. Communication is 
that part of the total process of interaction which has been described by Huntington (1958) as ". . . the way the actions of each person repeatedly infiuence those of the other in an unfolding sequence" (p. 45). Ruesch and Bateson's definition seems fitting for the purpose of this project since it includes all forms of communication and also provides the possibility of analyzing change.

\section{Levels of Communication}

Ruesch and Bateson (1951) discussed four levels or networks of communication which can influence any relationship, including that of marriage. These levels are Intrapersonal, Interpersonal, Group, and Culture.

The intrapersonal communication network is distinguished by a single participant, the individual himself, with both the origin and destination of the messages located within the sphere of one organism. Error correction is difficult, since the system of codification cannot be examined directly by more than one person (Ruesch and Bateson, 1951). What the individual brings to marriage is at least partially determined by his inner communication system.

Interpersonal communication, one to one, is characterized, by an exchange of receiving, transmitting, and evaluating messages. Correction of information is possible since both the origin and destination of the 
message may be known to the sender and receiver. This permits information items as they are transmitted and received to complement each other,".. but the complementation is never complete. . The human individual can never perceive himself perfectly in relation to others" (Ruesch and Bateson, 1951, p. 280). This assumption is jmportant in the marriage relationship particularly in the perception of one's own role and the role of the partner.

Group network communication is characterized in two ways: first, by "one person to many," or primarily as a one-way flow of messages from the center to the periphery; or one more active in transmission with many concerned with receiving. Second, by "many persons to one," or a one-way flow of messages toward the center (Ruesch and Bateson, 1951). The marital relationship can thus be influenced by others outside the marital pair--kin, friends, employeremployee, fellow employees, and all other groups. How this influence affects the marital pair will in turn affect their own communication system and roles.

The fourth communication network, cultural is also an important communication influence to the two persons who constitute a given marriage. This network is described as the "unperceived system." The individual does not recognize the source or destination of messages with both source and destination unknown. The communication moves from 
"many to many." People are often unaware of being either receivers or senders of messages. "Rather the messages seem to be an unstated description of their way of living" (Ruesch and Bateson, 1951, p. 281-2), From this cultural network come messages about symbolization, language, ethics, tradition, child rearing practices, trade customs, ceremonies, and theories of man's relationship to the universe and to his fellow man. All of these cultural components are communicated to each person in whatever culture he may originate and live. All influence the individual's personality and to a considerable degree determine: the elements which he brings to any relationship including that of marriage.

Lidz (1963) writes about language as one of the important means of communication, pointing out that ". . language is an inherent part of the culture and in itself forms a major determinant of how a person thinks" (p. 79). He adds that language ".. . permits and delimits the way in which one thinks so completely, that one can scarcely grasp that persons raised in other cultures have very different, but equally valid ways of experiencing and of thinking according to other systems of logic" (p. 79). Lidz, in his statement, has added a dimension to Ruesch and Bateson's position as stated above. 


\section{Power}

Communication is the expression of power. Blau (1.964) describes power as the ability of an individual to get what he wants without having to modify his own conduct, This definition, because it is comprehensive, will be used in this chapter.

Briar (1964) points out that each family has to solve the problem of authority and power with many patterns developing. The more powerful members of a family set the style and ". . predominate in the pattern of interactions" (Murrell and Stachowiak, 1965, p, 17). The power is usually interpersonal and comes from ". . alliances and deals, and certainty of power" $(p, 17)$. The individual in the family holding the most power is the person who can award favors, withhold recognition, and offer criticism or rejection.

Heer (1963) lists five possible bases of family power:

(1) external social control, (2) the prior internalization of norms, (3) discrepancy between actual return and return expected under an alternative to the existing marriage or family, (4) relative competence, (5) relative involvement ( $\mathrm{p}$. 139).

Since the amount of power determines authority in decision making, power is a relevant factor in pattern formation as the rules for interaction are established 
between the marital pair. Power, as a control factor, exists to the degree that ". . . it is perceived or accepted by those to whom it is directed" (Yelaja, 1965, p. 516).

\section{Function of Communication}

The functions of communication described by various authors vary almost as widely as do the definitions of communication itself. The functions of communication include the maintenance of everyday relationships between individuals, groups, and nations, Communication machinery is utilized in making decisions. Communication is also the instrument for ". . socializing new members of society" (Schramm, 1963, p. 13-15). Communication is coming to know ourselves through others' responses to us. Communication can also be the means of supplying entertainment.

Communication maintains everyday relationships between individuals, groups, and nations by engineering change and keeping strain at a tolerable level. It also satisfies the basic need for humans ". . to get close to one another" (Polansky, 1965, p. 1), through the channel of the spoken word. Schramm (1963) also expresses this thought when he says that we need communication 
- . simply to maintain the every day relationships of human beings who must live in proximity and must adjust to each other's needs and quirks and maintain a remarkably efficient and rewarding existence (p. 15).

The above statements are adaptable to the marital relationship in describing the essential function of communication between husband and wife. "A great part of the daily interaction of marriage partners is talk or other forms of communication" (Folsom, 1958, p. 113).

Communication is an essential tool of decision making. To reach a decision it is necessary to perceive incoming signals; to evaluate ". . which involves memory and the retention of past experiences" (Ruesch and Kees, 1956, p. 6); and then to transmit and express the decision and the information upon which the decision was based. Decision making is a basic element of all interpersonal and group relationships.

Karlsson (1963) discusses socialization as transmitting through linguistic communication ". . the fruits of experience from generation to generation, gradually accumulating and institutionalizing techniques of coping with the environment and for living together that each child must acquire" (p. 78). Through this process, the individual learns how to view and evaluate his behavior and act with reference to himself and to 
others,

The concept of one's self is communicated to him from others' responses (Stryker, 1959). This process, both gradual and continual, begins with the earliest moments of life, and has major influence on the developing personality, and continues through all of life's stages, including that of the marital relationship.

Karlsson (1963) in considering the marital relationship lists the functions of communication as letting the spouse know of role expectation which in turn notifies each marital partner of the adjustments each is required to make; letting each spouse know from the other the feeling of love and tender emotions each has for the other; and transmitting feelings of respect and admiration. Communicating dissatisfactions enables the other spouse to minimize them and is a prerequisite for all adjustment.

Entertainment, to amuse and direct (Babcock, 1958), is an important influence whether this communication comes through individual contemplation, or from the written or spoken word addressed to one or to manj. Entertainment can turn one's thoughts to the past, to the present, or to the promise of tomorrow. Such communication can be very personal, and may evoke emotional response which can influence behavior. "Man's concept of the world is acquired through social action and communication, and these acquired views are the 
foundations upon which will rest the future organization of his surroundings" (Ruesch and Bateson, 1951, p. 35). Communication may not always achieve "healthy" goals, Communication and interaction are processes which are vilnerable to distortion and abuse. The next chapter describes this form of dysfunction in detail.

\section{Communication Determinants}

Communication will be discussed with respect to three general determinants of effective communication: personality, social, and cultural factors.

\section{Personality}

Personality, the subject of Chapter III, is discussed here only in relationship to communication. Ehrenwald (1963c) points out that man's communicative behavior ". . must have started when and where he made his first appearance: in the family" (p. 191). The mother-infant relationship begins to shape the personality of the infant. The child's early communication is preverbal or nonverbal. The mother's response to the infant plays a significant part in how the child learns to communicate.

Ackerman (1958) has described personality as ". . the product of the interaction and merging of the individual organism and its environment. . ." (p. 48) 
Mowrer and Mowrer (1961) write about personality ". - in terms of the role of the individual in the group" (p. 30) pointing out that this conception of personality began in part with William James' statement that the "'. . Individual has as many selves as there are persons who recognize him and carry an image of him in their minds" (p. 30). Personality develops over time and with each experience from infancy to adulthood.

Iuckey (1964) describes the marriage relationship as largely depending upon "... what a person thinks he is and what he thinks the other person is" (p. 136). Understanding and communication are based on these perceptions, and are factors in marital satisfaction.

Barbara (1963) indicates that the healthier personality and the individual with more awareness is also the person who creates the most accurate map of himself, most realistically sees himself, and is the person who is able to ". - verbalize facts, situations, or feelings as they are and not as they should be" (p. 173). Personality is thus thought of as a determinant of communication and provides a focus for Harper's (1958) ". . first prerequisite for genuine communication of feelings" in marriage in "an atmosphere of safety. The spouse. . must feel it safe to say how he or she really feels": (p: 109): Such safety comes from a spouse's "self-confidence, self-respect, and self-love; ... strength of ego; conception of (the mate's) 
personality; . . prizing of forthrightness; . . conviction of strength of (the spouse's) love..." (p. 109).

In harmony with Harper's statement is Polansky's (1965) observation that individuals with ". . . unre-solved problems in the Schizoid spectrum" (p. 35) can not tolerate closeness with another human being nor permit themselves to trust. These persons would not be able to communicate that which would threaten their personal involvement and thus would not be able to form a close relationship in marriage, nor to communicate adequately on an interpersonal level.

Social

Wolfe and Snoek (1964) point out that social position is ". - essentially a relational concept, indicating the person's relationship with a social system and with other members of that system" (p. 431). An individual can have several social positions, each with a different social system and with other, or sometimes with the same, individuals. A person's behavior in any given position will be determined by internalized influences such as his own background, training, personal needs, aspirations, and goals as well as by forces originating in the environment. 
Social position is a determinant in communication. Social position prescribes to a considerable degree with whom and in what manner one should communicate. Communication can also be affected by both internal and external forces. This, in turn, can affect the relationship of all the individuals, directly and indirectly, concerned. In other words, a man's position in a business firm will not only serve as a clue as to how and with whom he communicates but will also affect his wife's communication patterns.

\section{Cultural}

Lidz (1963) points out that one of the cardinal functions of the family is ". - the transmission of the basic adaptive techniques of the culture to the children" (p. 112). Language has a central role in the parents' "nurturing and directing the child's linguistic abilities." Language is used by man ". . . to transmit and assimilate the instrumentalities and institutions of the culture" (Lidz, 1963, p. 113) which man needs for adaptation. Man is also ". . dependent upon learning useful and valid meanings to enable him to be adaptable to new conditions" (Lidz, 1963, p. 113).

Culture becomes a personal component transmitted to each individual from the particular environment and circumstances of his own life. For instance, words not only 
represent ". . . the culture's language and their shared meanings" but words also take on particular meanings through "an individual's idiosyncratic experiences with the symbol and with what it denotes" (Lidz, i963, p. 88).

Communication Patterns: Some Relevant Concepts

Various authors have tried to conceptualize marriage interactional patterns in a number of theoretical ways. The concepts used include roles, need complementarity, homogamy, homeostasis, and cohesiveness. These concepts will be described within the framework of communication as this is discussed in the literature.

Roles

Karlsson (1963) states that there are two positions in marriage with each spouse having his particular role expectation. There are four basic role differences in each marriage: the husband and his role and how he sees his wife's role; the wife and her role and how she sees the husband's role. Marital satisfaction comes from two sources: the roles each partner plays and the expectation of roles of the spouse. Karlsson (1963) states that communication is a basic process in marriage, and that communication about role-expectations, intentions, and feelings of love and respect must occur. Burgess (1926) 
points out that ". . every person has, with more or less awareness, a conception of his role, not only in society, but in all the groups of which he is a member. He has a conception of his own role in the family and of what roles each family member should have" (p. 5).

Marriage partners maintain relationships outside the marriage. These include such relationships as employeremployee, kin, friends, business, and social agencies; in fact, any occasion which brings about any form of communication between two or more people. Each spouse carries a variety of roles depending upon the interaction of the moment. Roles and role expectations alter with time and events. The ability to modify role to meet change determines the effects of each crisis. "Inadequate methods of meeting change multiply until the family members are unable to adequately satisfy the interpersonal needs of members" (Murrell and Stachowiak, 1965, p. 15).

Complementarity

Another pattern, promoted especially by Winch (1952), is "need complementarity" in mate selection and marriage. This theory is based on the premise that each individual seeks ". - within his or her field of eligibles for that person who gives the greatest promise of providing him or her with maximum need gratification" (Winch, p. 406). Ktsanes (1955) explains that this theory covers at least 
two possible types of complementary patterns between married couples: first, a theory based on the difference in the intensity of identical needs; and second, a theory based on the difference in the kind of need.

Rosow (1957) points out that most of the studies of need complementarity theory are limited since they do not take into consideration the changing needs of the partners.

\section{Homogamy}

Homogamy can be defined as the tendency for "Iike to seek like in mate choice." This suggests selection in the direction of self image with similarity in such characteristics as ". . biological, temperament, social and cultural background, age, race, ethnic group, previous marital status, interests, religion, and intelligence" (Kernodle, 1959, p. 149). Communication would be an essential process in the transmittal of these characteristics between the marital pair.

Homeostasis

Homeostasis is equated with "control theory" by Jackson (1959, p. 126) and is described by Meissner (1964) as follows: "Family behavior is perceived of as circular rather than linear as governed by homeostatic patterns of interaction which operate within the transaction system to 
preserve the balance of forces and needs" (p. 23). Montalvo (1963) refers to communication as a means of maintaining homeostasis in that this is used as the method of feedback which can affect behavior or outcome so that the agreed upon balance is maintained, This can serve in healthy as well as dysfunctional families. Titchener, et al., (1963) points out that homeostasis is balance or equilibrium achieved through adaptation of family members both as individuals and as members of the family unit. Communication, organization, control, and perception are essential elements in the adaptive process.

\section{Cohesiveness}

Marital cohesiveness or the strength of the marital relationship can be considered as the ". . direct function of the attractions within and the barriers around marriage, and an inverse function of such attractions and bartiers from other relationships" (Levinger, 1963, p. 19). There are many cohesive forces. Among these are emotional attachments, meeting of individual needs within the system, and valuing the system of marriage itself. Disruptive forces are those opposite to the ones referred to as cohesive. Both cohesive and disruptive forces can occur from within and from outside the system. (Karlsson, 1963). 
A major factor of cohesiveness is the ability of the marital partners to communicate their thoughts, feelings, plans, and hopes to each other. Feople vary in their ability to communicate. This can be true of individual members of a family as well as individuals within a particular socio-economic culture (Komarovsky, 1964). When communication is not free, the marriage may become less cohesive. The marital partners are then more likely to look to children, relatives, friends, employment, and other individual pursuits as a major means of satisfaction. In other words, communication, particularly through the spoken word allows humans, marriage partners, to "get close". (Polansky, 1965, p. 1).

\section{$\underline{\text { Summary }}$}

Communication, that is, the process of influence, is a vital part of the life of every individual. Communication influences the development of personality, and affects all interpersonal relationships. Communication makes it possible ". . . to know what we are through others' responses to us" (Stryker, 1959, p. 116). Communication in marriage is an essential quality in developing marital patterns. The cohesiveness of the marriage depends to considerable extent on the ability of the spouses to communicate. Communication can serve not only to establish "healthy" marital patterns but can also 
produce disruptive forces. The next chapter considers this statement in some detail. 


\section{CHAPTER V}

\section{MARITAL INTERACTION PATTERNS}

The present chapter examines what is actually happening in maxriage and how some of the interactionists have been able to identify patterns, how these were classified, and the interrelationship of patterns identified by some clinicians. By patterns is meant repetitive sequences of actions, somewhat automatic, which are used by families in adaptation (Titchener et al, 1963). Current patterning will be placed in context by a brief history of some early awareness of group and family behavior and some early attempts to categorize behavior into patterns.

\section{Early Recognition of Behavior Patterns}

From the literature it appears that behavior patterns in large groups were recognized earlier than those in families. In this respect the more bizarre phenomena caught the imagination of writers. As early as 1832, J. F. K. Hecker (1859), in Epidemics of the Middle Ages, attempted to show how the individual was bound to the group by imitation and compassion. He described many epidemics of mental disorders.

In 1841, Charles Mackey (1932) pointed out in Memoirs of Extraordinary Popular Delusions an interesting delusion which occurred during the Crusades when hundreds of thousands of people acted on a shared belief, irrespective 
of the groups involved with maneuvering, power struggles, or other material gains.

In 1877, Lasègue and Falret (1964) published their work on folie à deux. This term applies to a mental disorder (usually paranoid.) which occurs at the same time in two close associates. This happens most frequentiy between a parent and child, husband and wife, or two sisters.

In the 1890's family breakdowns were considered in terms of 'intra-family' rather than in terms of 'interaction'. What clinicians now regard as symptoms (drunkenness, laziness, etc.) were seen as causes, and attempts were made to change the families through personal influence and persuasion. Diagnostic thinking then turned to preventive measures such as social reform in housing, working conditions, and health care (Rich, 1956).

By the 1920's social workers had become more knowledgeable concerning social and psychological variables. Emphasis was placed on interaction within the family following Burgess' (1926) article on "The Family as a Unity of Interacting Personalities." This article was a conscious effort to view the unity, growth and change of the family as a product of its interaction. During the depression years there was a growing awareness of the need to identify the role of family interaction in the family's ability to withstand crises, 
In an effort to classify the families who could withstand the ordeal of economic loss with the least strajn, Robert Cooley Angell (1936) studied fifty families who had received public assistance for a year. The families were divided into four primary types: 1. Integrated, highly adaptable; 2. Integrated, moderately adaptable; 3 . Integrated, unadaptable; 4. Unintegrated. By 'integrated' Angell meant ". . bonds of coherence and unity running through family life, of which common interests, affection and a sense of economic interdependence are perhaps the most prominent" ( $p$. 15). By 'adaptability' he meant the flexibility of the family as a unit. He concluded that even a moderate degree of adaptability would pull families with any integration through all but the worst crises.

In a study of families' adjustments to crises due to war-time separation and reunion, Reuben Hill (1949) found that

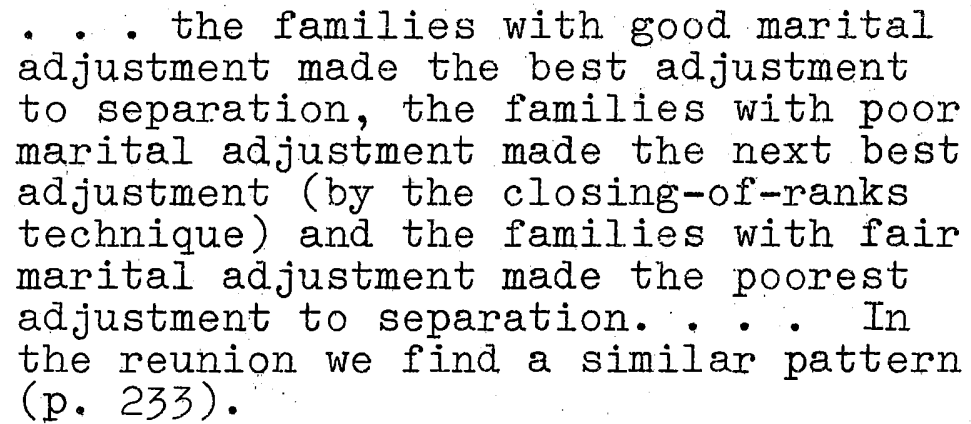

Hill listed six "jngredients" for patterns which predicted family success in adjusting, and which seem directly 
or indirectly related to interaction:

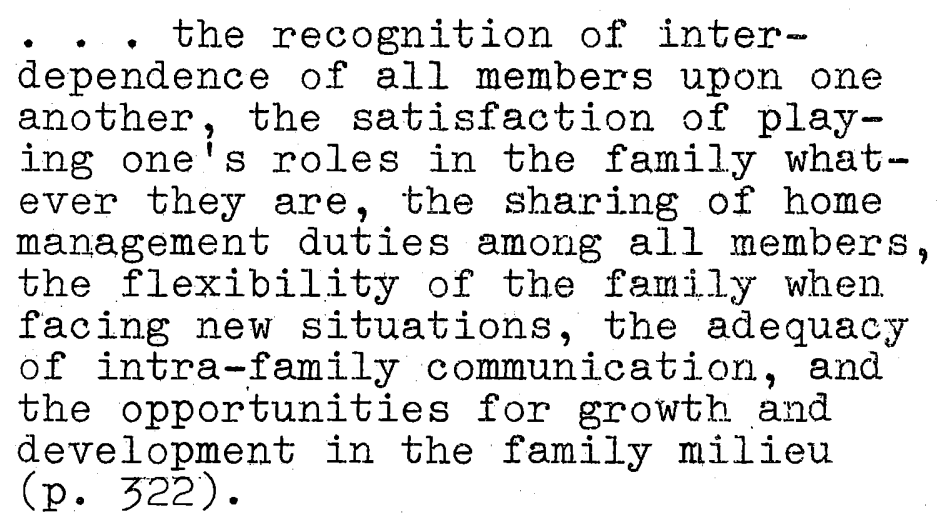

Some patterns of behavior which were identified very early have been highlighted, as well as the progression in diagnostic thinking of social workers from intra-family causes of family breakdown through extrafamily pressures and to interaction within the family. During the depression many studies attempted to discover the effect of particular situations on a family's adjustment. Much theorizing and research continues in the area of identification of the variables which operate in patterns of marital and family interaction.

Framework For Understanding Interaction Patterns

Each person enters marriage with the hope that the relationship will surpass all others in intimacy and permanence. Each brings personality traits and other determinants which affect the capacity for adjusting or coping. These determinants may be thought of as 
resources which one brings to the marriage. They include many things which each has incorporated into his 'self,' such as pattern of the like-sex parent, psycho-social defenses, expectations, ethnic background, religion and depth of commitment, constitutional factors, and social class. Marriage, in reality, becomes a fitting together of the two personalities and other determinants brought to the marriage.

Conceptualization of some variables which operate in marital interaction have been discussed in previous chapters. The difference in the use of each variable determines the type of interaction pattern which develops. The pattern may be functional, which means that there is an effective means of problem-solving, or dysfunctional, which indicates an ineffective means of problem-solving.

Interaction is more easily understood and analyzed within a framework. Such a framework developed by Hess and Handel (1959) considers five basic processes in a family. these involve individual effort and, at the same time, considerable interaction between family members. All five processes seem relevant for even the most laissez-faire family or marriage and form a framework of patterns toward which families strive either consciously or unconsciously. They are: 
1. "Establishing a pattern of separateness and connectedness."

2. "Establishing a satisfactory congruence of images through the exchange of suitable testimony."

3. "Evolving modes of interaction into central family concerns or themes."

4. "Establishing the boundaries of the family's world of experience."

5. "Dealing with significant biosocial issues of family life, as in the family's disposition to evolve definitions of male and female and of older and younger" (p. 4).

In analyzing the interaction of five 'typical' families, Hess and Handel considered that performance in these processes gave shape to the families' lives.

A description of the way a marital interaction pattern is formed can be better understood by considering the striving toward separateness and connectedness that is involved. In the beginning stages of a marriage, there is exploration of the new roles of husband and wife and how they fit together. Each partner expects to have his individual needs met and these expectations are extended into the interaction which ensues. Each partner attempts to understand the other and to establish some consensus in the idealized 'world of their own' which is in the making.

In striving for connectedness, however, one or both is faced with a threat to his autonomy. The concept of consensus may be modified because of role strain, and a 
decision concerning the amount of separateness and connectedness in the marriage is made by the partner with the most power. In other areas of the marriage the same variables operate in the interaction process. Through repetition interaction patterns eventually evolve.

The concepts of 'separateness' and 'connectedness' have subjective meanings to each individual, and each couple develops its own patterns in its own manner. In observing many marriages it seems apparent that patterns resulting from this particular process range the whole continuum from emotional relaxation and creativity on the functional end to autistic or psychotic behavior on the dysfunctional end (Hess and Handel, 1959).

In this framework the five processes are not discrete; each is carried on simultaneously with the others. The myriad ways of accomplishing them complicate the identification of resulting interaction patterns in a marriage.

\section{Marital Interaction Patterns}

Most of the literature concerning patterns of marital interaction comes from clinicians, psychotherapists, and others who base their pattern classifications on experience and knowledge gained from direct contact with people who have marriage problems. They have analyzed and organized their findings in order to have some way of 
looking at and working with what is happening in a marriage. Organization of experience into patterns provides a basis for actual diagnosis and treatment. For this reason, emphasis on dysfunctional patterning has taken priority over the functional in the literature.

Patterns are identified in broad and general terms. They are only descriptive, as it is extremely difficult to grasp the large number of variables and at the same time evaluate the use a marital couple makes of these variables in their own pattern. Clinicians need to examine the process of interaction as a whole in order to focus on particular areas of conflict.

\section{Determinants of Disturbance in Marriage}

Some authors use their own particular criteria in determining when a marriage is disturbed, before identify ing the dysfunctional pattern of interaction. SarwerFoner. (1963) finds that

One of the major determinants of a reasonable, versus an unreasonable marriage, is the amount of mutual criticism and derogation with which the marital partners assault each other. Without this mutual destructiveness and with mutual support for the partner's defenses--the marriage remains relatively stable despite gross pathologic traits (p. 38). 
Mathews and Mihanovich (1963) suggest that empirically

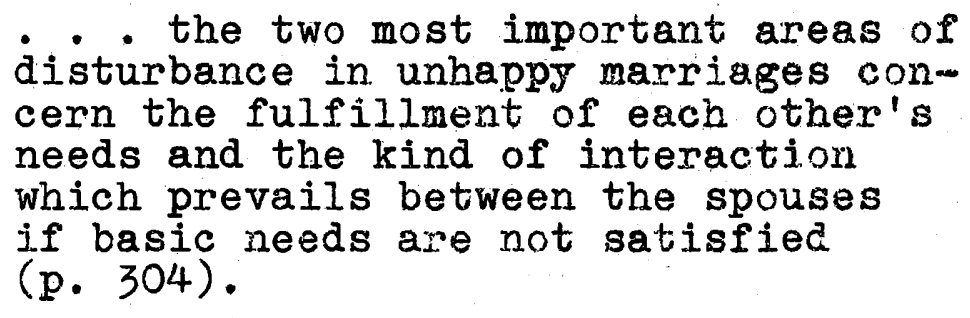

Ackerman (1958) says that marital disorders are demonstrated clinically as ". . . (1) failure of reciprocity of satisfactions and (2) conflict" (p. 154).

Other writers distinguish between function and dysfunction in marital interaction from the point of view of homeostasis, equilibrium, or balance. Montalvo's (1963) "homeostatic transactions" in dysfunctional families ". . are truly adaptive in their operation, but . . the 'sameness' that they try to maintain is that which has been established, rather than the transaction that will allow them to grow" (p. 116). The SpiegelKluckhohn transactional approach, as it is discussed by Spiegel and Bell (1959), differentiates 'sick' from 'well' families by their handling of role and value conflicts. In 'sick' families a too rapid attempt to change too many values results in ". . . a disequilibrium in their relations with each other, with their children, with relatives, and others" (p. 140). They find, bowever, that 


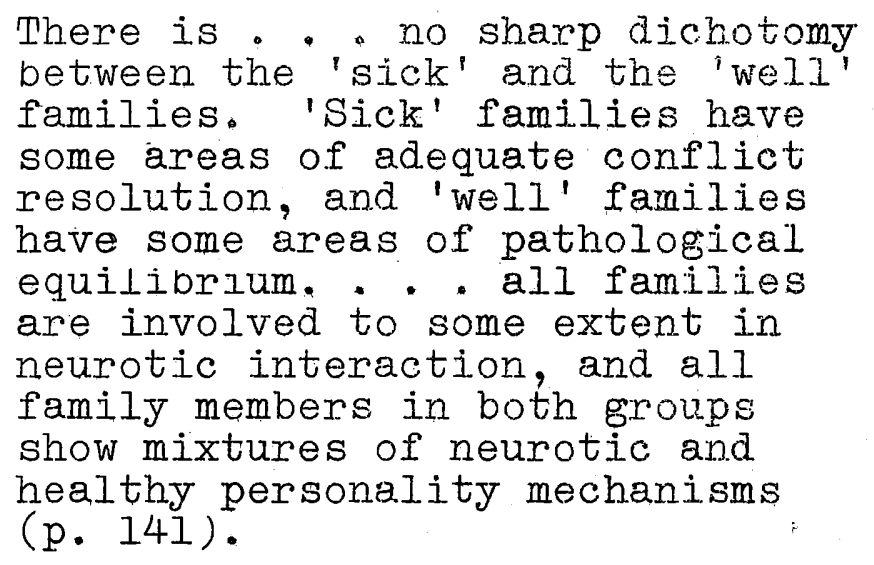

Ackerman (1958) states succintly that "Effective adaptation requires a favorable balance between the need to protect sameness and continuity and the need to accommodate to change" ( $p .85$ ).

\section{Ehrenwald's Patterns}

Jan Ehrenwald (1963a) identified five major patterns of interaction. He developed these from a study using An Inventory of Traits and Attitudes "contained in a broad spectrum of more or less habitual ways of relating" (1963b, p. 12l) which were observed in members of family groups. The patterns range from functional interaction, in what could be considered a well-adjusted family or marriage, to dysfunctional interaction, to the point of breakdown, failure, or psychosis. The patterns start at the functional end of the continum and extend to the dysfunctional: (1) Sharing, characterized by a givingsupportive-affectionate relationship; (2) Contagion, described as "a sharing of sick, neurotic or other 
interpersonal attitudes" (Ehrenwald, 1963a, p. 12); (3) Complementary, including the sadomasochistic, domirant w submissive, controlling-compliant relationships; (4) Rebelizion and resistance, used in response to controlling, domineering or rigid authoritarian attitudes in families; (5) Incompatibility, where there are practically no functional interrelationships (Ehrenwald, 1963a).

Ehrenwald (1963b) considers contagion to be the ". . maladaptive counterpart to patterns of sharing" (p. 126). He found in the study of one family that this pattern was responsible for the spread of neurotic disturbances both horizontally and vertically through several generations. Contagion was identified as a pattern in obsessive-compulsive families and those with psychopathology such as alcoholism, delinquency, homosexuality, and incest. He concluded that it was not the nosological entity which was transmitted but the patterns of interpersonal relationships.

In identifying major patterns of family or marital interaction, Ehrenwald uses psychological rather than interactional terms. An example of the pattern of contagion defined in interactional terms seems, however, to indicate a meaning similar to Ehrenwald's definition: 


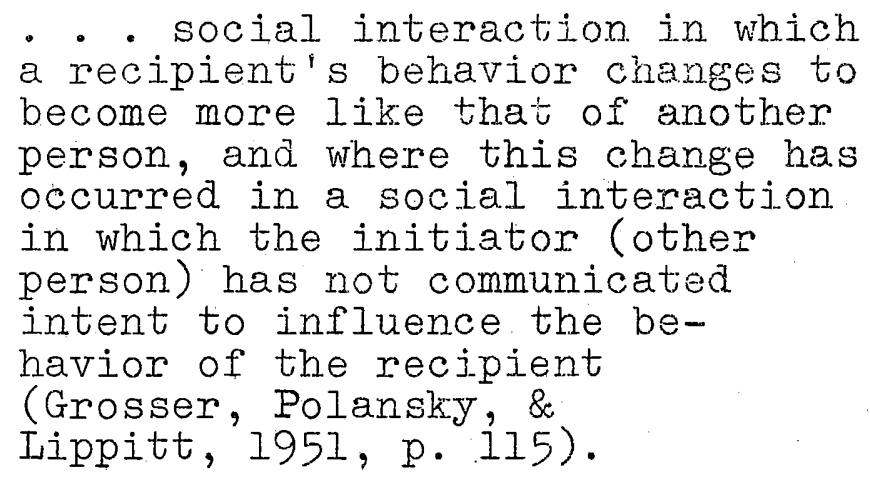

Mittleman's Neurotic Complementary Patterns

Bela Mittleman (1956) classified the dynamics of neurotic interrelations into five complementary patterns:

(1) Sado-masochistic.

(2) ". . emotional detachment on the part of one partner (usually the man) with an intense, open demand for love on the part of the other (usually the woman)" (p. 82).

(3) ". . . mutual attempt at domination, coupled with a violent defense" (p. 83).

(4) "Neurotic illness with a plea of helplessness on the part of one mate and an attempt at extreme considerateness on the part of the other..." (p..83).

(5) ". . . a syndrome where periods of helplessness and suffering are followed by periods of intense self-assertion on the part of one mate, and periods of shouldering responsibility followed by a disappointed desire for love and support on the part of the other" (p. 84).

Mittleman (1956) stresses the tendency of couples to ". . complement each other in such a way as to perpetuate their pathological reactions through an intrapsychic vicious circle of reactions" (p. 87). 
Although Mittleman's patterns generally can be included in or are comparable to Ehrenwald's complementary patterns, pattern two, "emotional detachment" coupled with a "demand for love", and pattern three, "mutual attempt at domination", might be considered as rebellion and resistance or varying degrees of incompatibility, depending on the amount of conflict present.

\section{"Marital Schism" and "Marital Skew"}

In families with schizophrenic patients, the Lidz group (Iidz et al., 1957) found "marital schism" and "marital skew" in family interaction. Schism is distinguished by parents' threats to separate, coercion, recrimination, and derogation; in skew, family relationships center around a dominant parent's pathology ". . . accepted or shared by the other" (p. 248). Schism is akin to Ehrenwald's rebellion and resistance pattern, or, again, to a degree of incompatibility. Skew is similar to the pattern of contagion.

\section{Berne's 'Games'}

Eric Berne (1961) is among those who are developing apparently new methods of psychotherapy described in interactional rather than personality terms. In his structural analysis, which is close to traditional 
psychiatry, Berne identifies three ego states in each person, Parent, Adult, and Child, any one of which may be used as a base for interaction. The 'Games' identified in transactional analysis are patterns of transaction or interaction between individuals who are in one or another of the ego states, involving hidden or ulterior notives or manevvers for personal gain. The 'Games' used in marriages and the way in which they are played determine the degree of dysfunction in any marital interaction. A common marital. 'Game' is called "If It Weren't For You" (p. 101), by which a partner can gain control of the marriage and protection against having personal inadequacies or problems revealed.

\section{Haley's Communicative Behavior Patterns}

Jay Haley (1963) defines an interpersonal relationship as ". - an exchange: of communicative behavior between two or more people" (p. 5). This type of behavior can be observed as opposed to individual processes which must be inferred; therefore, the emphasis is on the relationship, not the individual. All relationships are defined and controlled by communicative behavior, which Haley has classified into three broad pattern groups: symmetrical, complementary, and metacomplementary. In the symmetrical pattern two people exchange the same type of behavior, striving for equality, which can become competitive. The 
complementary pattern includes different types of behavior on a superior-inferior basis. Maneuvering for control of the relationship is metacomplementary. Haley defines a pathological relationship as one in which one person tries to gain control while denying that he is doing so. The type of communication used in this maneuver is termed a 'Paradox'.

Haley, a communication analyst, developed his ideas from the work of the research group who explored the nature of communication and developed the concept of the "double bind" (similar to Haley's Paradox) in relation to schizophrenia. After noting the lag in the development of terminology other than that used to describe the individual, Haley predicts that ". . . the ultimate description of relationships wili be in terms of patterns of communication in a theory of circular systems" (p. 4).

\section{Some Comments on Patterns}

Marital interaction patterns have been identified independently by a number of clinicians. General similarities in some of the patterns support the assumption that these patterns are valid. Some patterns"are described in terms of the personality, others in terminology descriptive of interaction. By remembering that the process of marital interaction involves and occurs 
between two personalities it is possible to see through the confusion caused by different terminology to the similar elements. Patterns of 'interrelationship' or of 'family relationships' imply interaction, and these elements in patterns are apparent, regardless of how they are described.

Few functional interaction patterns are identified. Emphasis has been placed on dysfunctional patterns because of the need for knowledge in treating disturbed marriages. It would be of value for practitioners to know what functional interaction patterns are, not only for comparison with the dysfunctional but also as guides in helping couples modify their own interaction patterns.

Complementary patterns seem to be the most generally noted. Those described in the literature are predominantly dysfunctional because of the clinicians' experience in problem areas of marital interaction. Complementary patterns, however, can also be functional, where the expectations and needs of each partner are satisfied by the other. Even in marriages where there is neuroticism or a degree of pathology in one or both partners a complementary pattern of interaction can make the marriage stable.

Mittleman (1956) and the Lidz group (Lidz et al, 1957) are among those who have identified patterns concentrated on certain types of interaction. Others, including 
Ehrenwald (1963), Berne (1961), and Haley (1963), Lave taken a broad approach to interaction in classifying patterns ranging from functional to aysfunctional. Each uses a different method of viewing interaction: Ehrenwald uses the effect of personality traits and attitudes on family relationships, Berne employs a combination of psychoanalysis and methods of communicating, and Haley uses 'communicative behavior.' The similarities in patterns, as noted, are apparent.

There is no generally accepted set of criteria used to develop the classification of interaction patterns. That so many have identified complementary patterns, for instance, does not seem to be coincidental, but whether or not the criteria or methods used are essentially the same is unknown. Concepts concerning interaction patterns and criteria used in classification need to be compared and evaluated for common factors. The development of a common interactional language would facilitate the identification and acceptance of these criteria.

The interrelationship of communication and interaction, or communication as interaction, does not seem to be recognized in some pattern classifications. Those of Ehrenwald (1963) and Mittleman (1956) appear to be based on the behavior or attitudes of couples or families as they affect interaction. Berne (1961) in his 'Games' and 
particularly Haley (1963) consider communication as an integral part of interaction, as is noted in some definitions in Chapter IV. The 'communicative behavior' described by Haley has the advantage of being observable rather than inferential and may prove valuable in research as a means of adding to knowledge about pattern formation. In spite of what has not been done and what needs to be done, patterns classified from clinical experience are valuable. Hess and Handel (1959) support the necessity for an alliance between experience and conceptualization:

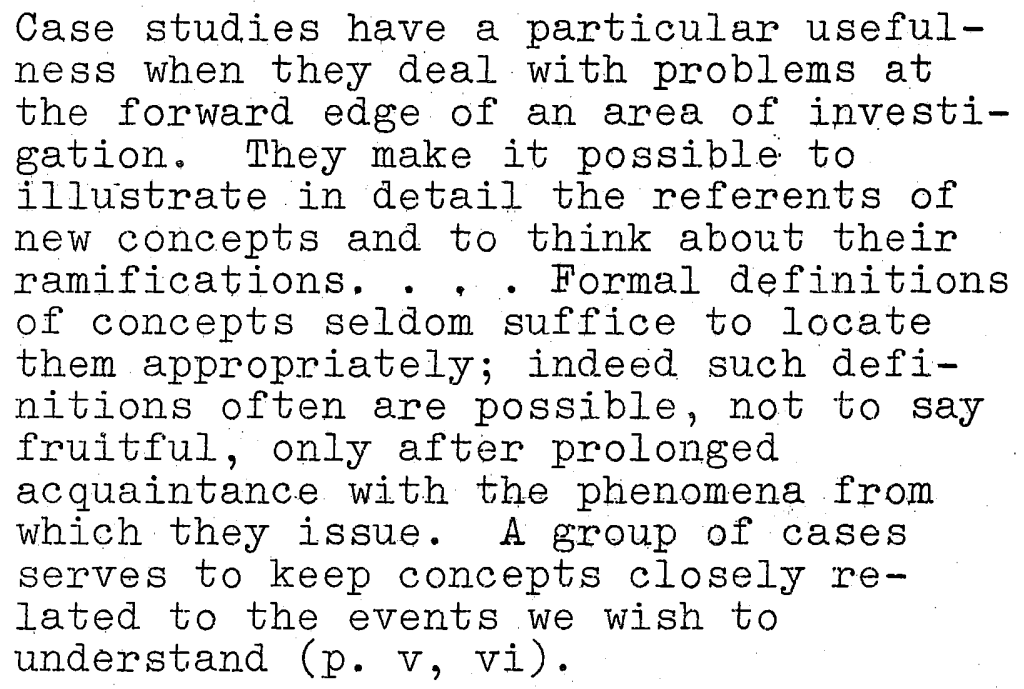

$\underline{\text { Summary }}$

The classification of marital interaction patterns is comparatively recent, as is the interactional approach. Knowledge of this approach and of patterns is as useful 
for social workers as it is for clinicians, and its use in practice gives an additional dimension to therapy for marital partners who have problems in the area of interpersonal relationships. 
CHAPTER VI

SOME MEA.SUREMENL ISSUES

FOR MARITAL INTERACTION STUDIES

Empirical studies of marital interaction are underm taken to determine its dimensions or to validate some hypothesis about it. Two methods frequently used in recent studies are direct observation of marital interaction in a laboratory setting and analysis of reports obtained from marital partners. This section of the report will discuss the usefulness of a general style of inquiry, but no attempt will be made to evaluate individual studies.

\section{Problems of Measurement}

Measurement of marital interaction shares all the problems of other studies of behavior. Selltiz et al (1960) summarize by saying:

Whatever the purpose . . four broad questions confront the investigator: (1) What should be observed? (2) How should observations be recorded? (3) What procedures should be used to try to assure the accuracy of observation? (4) What relationship should exist between the observer and the observed, and how can such a relationship be established (p.205).

To add to the problems, a large proportion of marital interaction is private and personal. 
A form of marital activity which is most readily available for recording and subsequent analysis is verbal interaction. Several authors suggest why it is worthy of study. Stryker (1959) feels that language is a peculiarly human emergent. As such it reflects how society structures its environment. Ruesch and Bateson (1951) assert that communication, which is necessary for a person to know himself or to know about relationships, is dependent on well-defined symbols among which language is the most important. Satir (1964) underlines the necessity of communication for marital interaction.

Whenever a person communicates he is not only making a statement, he is also asking something of the receiver -. The receiver, in turn, must respond, because people cannot not communicate. Even if the receiver remains silent, he is still communicating ( $p .78$ ).

Polansky (1965) believes that verbal communication has high value in human relationships.

My own feeling is that just as subhuman anthropoids can proceed so far, and no farther by means of prelinguistic thinking, so in therapy patients can move only so far by nonverbal methods ( $p$.44).

Direct Measurement of Marital Interaction

Direct measurements are concerned with observing 
and describing actions. In order to observe marital. interaction investigators present a husband and wife with some task on which they are requested to work together. This both initiates activity and limits its extent. The task must be one that seems important to both partners and one which gives both partners equal opportunity for participation. The conditions under which this activity takes place can be more easily controlled in a laboratory setting than in the home environment.

The great advantage of direct observation is the chance to record action as it happens. People's reports of what they do are often inaccurate. This is shown in the Kenkel and Hoffman (1956) study where participants' reports about their actions in a test situation did not correlate highly with what they actually did.

Direct observation can note actions other than verbal exchanges. People are probably less likely to distort their actions than their reports about actions. The limitations imposed by a test situation give a good basis for comparison between couples on performances. This means that each couple is presented with the same task and that observations are made and interpreted in the same way each time.

There are some disadvantages to direct observation 
of marital interaction in a test situation. The duration of the action is limited to a short time, and the observed action may not be representative of a spontaneous, unstructured situation.

Haley (1964) felt that family or marital interaction could best be evaluated by direct observation. This avoids the distortions of participant perceptions. He recognized the difficulties in interpretation of unstructured family activity in the natural home setting and also the possible bias a structured, laboratory setting introduced. He chose conversational interchanges as the most normal means of communication. Family groups of father, mother, and one child were given fairly neutral questions to discuss on which presumably each member would have equal right to speak. The sequence of responses -- which person spoke following which other -- was recorded mechanically through separate microphones for each individual. The resulting patterns were compared to completely random response patterns. The author concluded that a family comprises an organization because patterns of response differed significantly from randomness. The degrees to which families differ could be compared, and families in which no member was receiving psychiatric treatment were found to respond in a more nearly random manner. Haley suggested that such randomness of response indicated greater 
flexibility in communication.

Though Parsons and Bales (1955) did not report original studies of marital interaction, the inferences they drew from work with small groups and in particular the classification developed for categorizing action (Parsons, Bales, and Shils, 1953) have had far-reaching influence. They saw all human interactions as partaking in varying degrees of instrumental qualities (task accomplishing or task deterring) and expressive qualities (promoting pleasant or unpleasant sentiments). They defined the nuclear family as a specialized subsystem of a culture with characteristics such as role fulfillment by individual members, similar to small groups. They hypothesized that husbands tend to specialize in instrumental activities and wives in expressive activities (Parsons and Bales, 1955),

Strodbeck (1951) devised a test situation where the interaction of husbands and wives could be studied directly. The couple was presented various situations with which they were equally familiar and asked to register opinions separately. They then compared their answers and were required to decide on a mutually agreeable response for each question. Measurement was made of the number and direction of reconciliations as an index of each partner's influence. An observer also utilized the 
Bales' system (Parsons, Bales, and Shils, 1953) to categorize the types of actions employed in reaching a decision.

Goodrich and Boomer (1963) set up a test of how husbands and wives reach agreement using charts of color gradations. Defiberate variations in the numbering on individual charts created confusion. The observed interaction was categorized along lines of involvement, accomplishment of the task, and maintenance of esteem.

Loveland, Wynne, and Singer (1963) devised a more complicated test situation in which areas of agreement must be reached. They included a child with the married couple in a family Rorschach. After previously completing individual Rorschachs, family members were asked to find areas of agreement on ink blot interpretations. An observer behind a one-way screen described nonverbal actions and recorded comments on the total actions. Conversation was tape recorded.

Elbert et al (1964) suggested a plan for studying family interaction which elaborates on the family Rorschach. To elicit projective material they employed a series of picture cards with concrete family situations. These were viewed by individual family members and then discussed in a group. The family also discussed six questions ranging from very neutral subjects to very 
loaded subjects such as description of a family fight. There was one nonverbal task -- the duplication of a wooden model. All actions were recorded by a concealed observer.

Kenkel and Hoffman (1956) and Kenkel (1959, 1961) engaged couples in reaching a decision about spending a sum of money. They felt that this task was sufficiently interesting and familiar to elicit representative interaction. In addition they varied the sex of the observer, obtained information on values held by the marital partners, and had the participants record their perceptions of their own activities in the test situation. The tasks were carried on in the presence of an observer who recorded actions using Bales' categories.

\section{Indirect Measurement of Marital Interaction}

Indirect measurement of marital interaction is concerned with how the situation appears to the participant. It is dependent on self-report by the participant. This report is verbal and makes use of either interview, questionnaire or projective material.

This method of observation has the advantage of access to material which is not directly observable. A. person's view of a situation is very real to that person. Information obtained by questionnaire is limited to 
written responses to set questions. It tends to assure the respondent of anonymity and give him time to consider his answer. Information obtained by an interviewer can include observations of behavior as well as answers to questions. Interviews can be used to obtain information from people who find a questionnaire too complicated or too much trouble to complete. Projective methods obtain information without revealing to the respondent what information is being sought. The subject's responses to some stimulus like an ink blot or a picture are interpreted by the investigator. This avoids the problems of a person's willingness or ability to reveal himself. The adequacy of projective material is determined by the quality of the interpretation.

There are some limitations on the nature of information which can be obtained by self-report. A person must be willing to make the report. He might not report something damaging about himself. He must be able to make the report. He might be unaware of some things about himself.

The following group of studies of marital interaction investigated participant perceptions of themselves, of their partners, and of the marriage relationship.

Karlsson (1963) employed questionnaires administered by an interviewer to marital partners separately to obtain. their assessments of satisfaction in the marriage and also 
individual sets of personality characteristics. He found that traits a member of the marriage perceived in the partner gave a better index of satisfaction than traits discovered by tests. His book is also very descriptive of communication within marriage and of ". . adaptability, which was tentatively defined as the ability to adjust without difficulties to different situations" (Karlsson, 1963, p. 79-80).

Rollins (1962), by methods which are not described in the abstract, studied marital stability and found coresion more strongly correlated with perception by marital. partners that they hold similar values than by actual consensus in values.

Winch, Ktsanes, and Ktsanes (1954) obtained information on the personalities of married pairs through interviews, case histories and projective tests. Their subjects were recently married and childless so that marital interaction would have had relatively little influence on their personalities. The authors proposed. the idea that couples simultaneously satisfy individual needs which are different or of different intensities. They found greatest substantiation for this view through needs discovered at a conscious level by interviews.

In a test of Winch's findings, Murstein (1961) administered a variety of individual tests in questionnaire form to childess couples married a short time and to 
couples married more than ten years. He found that there was no simple dichotomy of needs in marriage. Among the newlyweds he did not find that the complementarity between the married pairs differed greatly from men and. women from the sample group matched randomly. In couples married a long time, he found a homogamous pattern of needs.

Buerkle and Badgley (1959) at Yale presented marital partners separately with questionnaires detailing marital conflict situations and offering a choice of four solutions. Solutions ranged from benefiting self to benefiting the partner and elaborated varying degrees of awareness of the partner's feelings. The authors arrived at a composite score for the couple. It was a high score if there was agreement on the resolution of the situations even if mates were unequal in sympathy. They found that altruism -.. the tendency to favor the other -- varied with the situation involved.

Hobart and Klausner (1959) attempted to measure communication and ability to anticipate the spouse's answer by use of individual questionnaires concerning barriers to communications and self-spouse ratings on a variety of characteristics. Mutual recognition of taboo subjects was found to be associated with marital adjustment. Insight into spousal self-rating on personal performance appeared to be more important than insight into spousal self-rating on marital roles performance. 
Levinger (1963) studied a family group through a combination of procedures. He observed performance on a variety of tasks, obtained parent assessment of family members by means of questionnaire, and obtained externai judgments about family members from a counselor or teacher who was familiar with the family. The author gives a very thoughtful and illuminating discussion of the limitations of any one line of inquiry and of the value of combining techniques. He also gives a brief historical review of studies on marriage.

\section{Summary}

This chapter has considered two general styles of measurement for marital interaction -- direct and indirect.

Direct observation is most useful for discovering and describing characteristics of marital interaction. It has the advantage of immediate access to a sample of behavior undistorted by the participant's perceptions. However, observations could be biased by the subject's awareness that he is being watched, or by the unrepresentativeness of the test situation.

Indirect methods of observation which rely on participant self-report are most useful for discovering what seems important to the individual member of the marriage. An individual's perception of a situation is the most compelling 
reality for that person. Information obtained through questionnaires and interviews reveals feelings about the marital interaction and has been useful in predicting cohesion in marriage. However, such material can be distorted by the respondent either willfully or unwillfully, and such material cannot reveal anything of which the respondent is not aware.

Valuable information could be obtained by reports from people who know the members of the marriage well and who will provide such a report. The Levinger (1963) study is one example of the use of this type of information.

A combination of techniques can provide information unavailable from use of a single technique. Findings in the Levinger (1963) study suggest that parental actions toward a child can be predicted from their attitudes toward him. It is likely that information about marital interaction could be greatly enriched by employment of a combination of techniques in a single study. 


\section{CHAPTER VII}

\section{SOME IMPLICATIONS FOR RESEARCH.}

Interaction, a complex phenomenon, is difficult to define, yet the everyday interaction of marital partners is so routine and commonplace that the participants are hardly aware of this continuing process.

In marriage two people come together bringing with them certain resources. These two independently motivated beings must organize their actions so that their contributions produce some mutual gratifications of each other's needs. The constant exchange of information with attempts to influence the other gradually results in a patterning of responses. These typical responses become the basic interaction pattern of the married couple. The patterning indicates an implied consensus when each spouse accepts the response of the other as appropriate.

The stability shown by the existence of patterns does not preclude change. Throughout the marriage patterns must be confirmed, modified, altered or replaced when conditions change and new needs arise.

This project attempts to describe the dimensions of the interactional approach in order to lay the conceptual groundwork for a series of empirical studies. A discussion of research implications in this context is limited to general questions that either need to be answered or are best 
answered by the interactionist. Specific hypotheses will not be proposed but the discussion will focus on two major issues on the interactional approach with some consideration of questions regarding personality, patterns, and communication. The aforementioned issues are the problems presented by the interactional definitions and the meaning of socialization in the interaction process.

The Problem of Definitions

The interactional approach is burdened with theoretical concepts whose definitions have not been made operational. The philosophical approach of George Herbert Mead is a provocative and stimulating tool for the interactionist. It provides a base that is sufficiently broad to support a variety of studies of the personality and the interaction process. Some studies have yielded significant findings using Mead's concepts. The difficulty lies in transposing the theoretical definitions into operational ones. Such concepts as the self and generalized other must be made much more explicit. As noted by Hill and Hansen (1960), research cannot proceed without a sound conceptual framework. This need for a sound structure is most pertinent to the interactional approach since the process studied is extremely complex and as yet only broady defined. 
The Problem of Socialization

The interactionist must concede the validity of Strykex's (1959) statement regarding the relevance of socialization to the interactional approach. The process of socialization begins with infancy and progresses throughout life. Through socialization the individual learns to adjust his behavior so it conforms more or less to the others' expectations. The individual must be able to predict how others will react to him if he is to behave appropriately. He must also learn the role of the other, or anticipate the other's response from his own behavior and examine and evaluate his own performance.

Early socialization cannot fully prepare a person for: later roles although socialization in later years builds on previously acquired attitudes and skills. Each person must be able to adapt to changed expectations of a modern, com-plex society. The limits of socialization in later life are related to the interaction of the biological capacities of the individual and the effects of learning or lack of it with the level of technology achieved by the society in its socialization methods (Brim, 1966).

The issue for the interactionist is to determine more precisely the relation between the interaction process and the socialization process. It is necessary to know when and why adult socialization occurs and to distinguish the 
types of interaction that are conducive to this change.

\section{Personality}

Personality is shaped and developed in part through interpersonal relationships. Although personality is a relatively stable component of marital interaction, change does occur as the individual adapts to new situations and roles. Research results are not conclusive as to the continuity of personality. There are very few studies of adult socialization which deal with the process by which society influences individual roles and in turn personality.

Becker (1964) points out that the degree of commitment has a relationship to personality change and that change may be transitory in nature, an adjustment to meet a particular situation.

Competence, as earlier described, has been defined as the ability to meet one's own needs as well as those of one's spouse. Commitment and competence can be powerful contributions by each spouse to the marital interaction. It would be important to define the effect of each of these factors on the personalities of the marital pair since satisfaction in marriage is related to the interrelationship of the personalities of the husband and wife. 


\section{Marital Interaction Patterns}

Marriage is a unique unity, the dynamic relationship between husband and wife. Each brings to the marriage an. individual identity gained from his particular socializing experience.

In early stages of marriage, ways of actine and reacting to each other apparently eventually develop into stable patterns. These interaction patterns may be functional or dysfunctional to the individual, the couple, their children or society. As an example, there have been many studies of families of schizophrenic children which indicate serious psychopathology in the parents. Fhrenwald (1963) cites studies of patterns of obsessions and compulsions which have been repeated in several subsequent generations. These patterns appear to be part of the socialization process of these families. It appears then that faulty interaction of these families hinders the healthy personality development of the children who then carry on these faulty interaction patterns into their own marriages. The significance for society is evident.

Society also affects the interaction patterns within a family. Migration, urbanization, industrialization, all have brought about the isolation of the nuclear family. This causes changes in socialization of the children and of 
the adults. More marital strain may result as additional needs of the marital partners must be provided by each other.

It seems clear that marital interaction is affected by changes of society which in turn is affected by the patterns of marital interaction. In this circular re.. lationship, dysfunction in any area can adversely affect individual lives, marital relationships and society itselfs.

The interactional approach is concerned with how effective interactional patterns are established; how agreement'is reached; and how the individual behavior patterns result in various types of marital interaction. Each of these factors demands further research if the process of interaction is to be fully understood. The precise determinants which regulate whether these patterns are to be functional or dysfunctional are not sufficiently clear.

\section{Communication}

Communication, defined to include all those symbolic processes by which people influence one another (Ruesch \& Bateson, 1951), is of major importance in examining interaction.

Verbal communication is the most measurable, the most accessible, and the most uniquely human way of expressing meaning. The product of communication is not merely the 
modification of the listeners" attitudes or behaviors, but the establishment of some degree of consensus. Since verbal. communication can be less ambiguous and more complex than nonverbal communication, it serves as a medium for clarjity ing issues and misunderstandings between the marital pair. Polansky's (1965) verbal accessibility studies have provided some interesting, though sometimes inconclusive, results. There is much research yet to be undertaken to test the valjdity of assumptions made. Among the factors requiring further research are the variations in accessibility among different attitudes; the relationship of verbal accessibility to personality structure; and the relationship of verbal accessibility to family patterns, subcultures, and defense mechanisms.

The significance of verbal communication: for marriage is incompletely understood; thus research questions should focus on the quality and quantity of messages and their impact on the personality, the interaction process, and the formation of patterns.

\section{Conclusion}

The greatest challenge for research, based on the interactional approach, is to clarify the existing concepts so that a consistent, useful framework emerges. The relation of socialization, personality, patterns, and communication to the interaction process is Iooseiy defined; however, it is 
through study of the specific interact that information concerning these areas is most obtainable. The complexity of the marriage relationship requires precise anajysjs if various components are to be properly understocd. 


\section{BIBLIOGRAPHY}

1. Ackerman, Nathan $W$. The psychodynamics of family life. New York, Ba.sic Books, 1958. 379 p.

2. Angeli, Robert Cooley. The family encounters the depression. New York, Scribnes, 1936. $309 \mathrm{p}$.

3. Aristotle. Politics. Tro by B. Jowett. New York, P.F. Colfier, 1900. 208 p.

4. Babcock, C. Merton. Purposeful communication. In: C. Merton Babcock"s Ideas in process. New York, Harper, 1958. p。309-363.

5. Barbara, Dominick A. Nonverbal commication. The Journal of Communication 13:166-173. 1963.

6. Bateson, Gregory. Formal research in family structure. In: Nathan W. Ackerman, Frances I. Beatman, and Sanford N. Sherman's Exploring the base for family therapy, New York, Family Service Association of America, 1961. p.136-140.

7. Becker, Howard S. Personal change in adult life. Sociometry 27:40-53. 1964。

3. Berne, Eric. Transactional analysis in psychotherapy. New. York, Grove Press, 1961. 270 p.

9. Birdwhistell, Ray I. An approach to communication. Family Process 1:194-201. 1962.

10. Blau, Peter M. Exchange and power in social life. New York, John Wiley, 1964。 352 p.

11. Blau, Peter M. and W. Richard Scott. Formal organizations: a comparative approach. San Francisco, Chandler, 1962。 $31.2 \mathrm{p}$.

12. Bonner, Hubert. Social psychology: an interdisciplinary approach. New York, American Book, 1953. 439 p.

13. Briar, Scott. The fomily as an organization: an approach to family diagnosis and treatment. The Social Service Review 38:247-255。1964. 
14. Brim, Orvile G. Jr. and Stanton Wheeler, Socialization after childhood, two eseays. New York, John Wiley, 1966. $116 \mathrm{p}$.

15. Buerkle, Jack $V$. and Robin F。 Bodgley. Couple roletaking: the Yale marital interaction battery.

Marriage and Family Living 21:53-..58. 1959.

16. Buerkle, Jack V。, Theodore R. Anderson and Robin F'. Badgley. Altruism, role conflict, and marital adjustment: a factor analysis of marital interaction. Marriage and Family Ijiving 23:20-26. 1961.

17. Burgess, Ernest Wo The family as a unity of interacting personalities. The F'amily 7:3-9. 1926.

18. Cherry, Colin. On human communication. New York, Science Editions, 1961. $333 \mathrm{p}$.

19. Cooley, Charles Horton. Human nature and the social order. New York, Scribner, 1922. 184 p.

20. Dewey, John and Arthur F. Bentiey. Knowing and the known. Bostion, Beacon, 1949. $334 \mathrm{p}$.

21. Duncan, Hugh Dalziel. Communication and social order. New Jersey, Bedminster Press, 1962. 475 p.

22. Ehrenwald, Jan. Neurosis in the family and patterns of psychosocial defense: a study of psychiatric epidemiology。New York, Harper-Row, 1963. $203 \mathrm{p}$ 。

23.

Family diagnosis and mechanisms of psychosocial defense。 Family Process 2:121-131. 1963。

24.

Family dynamics and communication theory. The Journal of Communication 13:191-198. 1963.

25. Elbert, Shirley et al. A method for the clinical study of family interaction. American Journal of Orthopsychiatry 34:885-894. 1964.

26. English, Horace B. and Ava C. English. A comprehensive dictionary of psychological and psychoanalytical. terms. New York, Jongmans Green, 1958. 594 p. 


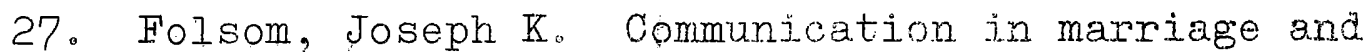
marriage counseling。 Marriage and Family Living $20: 113-116.1958$.

28. Foote, Nelson $\mathbb{N}$. and Leonard S. Cottrell Jr. Identity and interpersonal competence. Chicago. University of Chicago Press, 1955. $305 \mathrm{p}$.

29. Goodrich, D. Wells and Donald S. Boomer. Experimental assessment of modes of confilict resolution. Family Process 2:15-24. 1963.

30. Gross, Neal Crasilneck, Ward S. Mason and Alexander W. McEachern. Explorations in role analysis. New York, John Wiley, 1958. 379 p.

31. Grosser, Daniel, Norman Polansky and Ronald Iippitt. A laboratory study of behavioral contagion. Human Relations 4:115-142。1951.

32. Haley, Jay. Strategies of psychotherapy. New York, Grune and Stratton, 1963. 204 p.

33. Research on family patterns: an instrument measurement. Family Process 3:41-65. 1964.

34. Harper, Robert A. Communication problems in marriage and marriage counseling. Marriage and Family Iiving 20:107-112. 1958.

35. Hearn, Gordon. Theory building in social work, Toronto, University of Toronto Press, 1958. 83 p.

36. Hecker, Justus Friedrich Karl. The epidemics of the middle ages. 3d ed. London, Scribner, 1859.360 p.

37. Heer, David $M_{\text {o }}$ The measurement and bases of family power; an overview. Marriage and Family Living $25: 133-139$ 。 1963.

38. Hess, Robert Do and Gerald Handel. Family worlds: a psychosocial approach to family life. Chicago, University of Chicago Press, 1959. 305 p.

39. Hill, Reuben。 Families under stress; adjustment to the crisis of war separation and reunion. New York, Harper, 1949. $4.43 \mathrm{p}$ 。 
40. Hill, Reuben and Donejd A. Fansen. The identification of conceptual frameworks utilized in family study. Marriage and Family Iiving 22:299-311. 1960.

41. Hobart, Charles $W$, and William Jo Klausner, Some social interactional correlates of marital role disagreement, and marital adjustment. Marriage and Family Living 21:256-263. 1959.

42. Homans, George C. The human group. New York, Harcourt-Brace, 1950. 484. p.

43. Huntington, Robert M. The personality-interaction approach to study of the marital relationshjp. Marriage and Family Iiving 20:43-46. 1958.

44. Jackson, Don D. Family interaction, family homeostasis, and some implications for conjoint psychotherapy。In: Jules $H_{0}$ Masserman's Science and psychoanalysis-individual and familial dynamics, Vol. II. New York, Grune and Stratton, 1959. p. $122-141$.

45. Jones, Dorothy. Binds and unbinds. Family Process $3: 323-334$. 1964。

46. Jourard, Sidney M. and Paul Lasakow. Some factors in self-disclosure. Journal of Abnormal and Social Psychology 56:91-98. 1958.

47. Kantor, Robert E. Schizophrenia and symbolic interaction. Family Process 3:402-414。 1964.

48. Karlsson, Georg. Adaptability and communication in marriage. 2d rev。 ed. New Jersey, Bedminster Press, 1963. 89 p。

49. Kenkel, William $F$. Traditional family ideology and spousal roles in decision making. Marriage and Framily Living 21:334-339. 1959.

50. Sex of observer and spousal roles in decision making. Marriage and Family Iiving $23: 185-186.1961$

51. Kenkel, William $F$, and Dean $K$ 。 Hoffman. Real and conceived roles in family decision making. Marriage and Family Iuving 18:311-316. 1956. 
52. Kernodle, Wayne. Some implications of the homoganycomplementary needs theories of mate selection for sociological research. Social Forces 38:145-152. December 1959.

53. Komarovsky, Mirra. Blue-collar marriage. New York, Random House, 1964. 395 p.

54. Ktsanes, Thomas. Mate selection on the basis of personality type: a study utilizing an empirical typology of personality. American sociological Review $20: 547-551$. 1955。

55. Lambert, William $W$. and Wallace E. Lambert, Social psychology. New Jersey, Prentice-Hall, 1964. 1.20 p.

56. Lasègue, Ch. and J. Falret. Ia folie à deux ou folie communiquée. Annales Médico-Psychologiques 18:321. 1877. (Translatied in supplement to American Journal of Psychiatry 121:1-23. 1964).

57. Ievinger, George. Supplementary methods in family research. Family Process 2:357-366. 1963.

58. Marital cohesiveness and dissoIution: an integrative review. Journal of Marriage and the Family 27:19-28. 1965.

59. Iidz, Theodore. The family and human adaptation. New York, International Universities Press, 1963. $120 \mathrm{p}$ 。

60. Iidz, Theodore et al. The intrafamilial environment of the schizophrenic patient: II. Marital. schism and marital skew. American Journal of Psychiatry 114:241-248. 1957.

61. Linton, Ralph. The cultural background of personality. New York, Appleton-Century-Crofts, 1945. 157 p.

62. Ioveland, Nathene T., Iyman C. Wynne and Margaret T. Singer.: The family Rorschach: a new method for studying family interaction. Family Process $2: 187-215.1963$.

63. Iuckey, Eleanor Braum. Marital satisfaction and its concomitant perceptions of self and spouse. Jourial of Counseling Psychology $11: 136-145.1964$. 
64. Mackey, Charles. Extraondinary popular delusions and the madness of crowds (a verbatim reprint, with reproductions of original illustrations, of the edition of 1852). Boston, I.C. Paige, 1932. 724 p.

65. Mathews, Vincent $D$. and Clement $S$, Mihanovich. New orientations on marital maladjustment. Marriage and Family Living 25:300-304. 1963.

66. Mead, George H. Mind, self, and society. Charles W. Morris (ed.) Chicago, University of Chicago Press, 1934. $401 \mathrm{p}$.

67. The philosophy of the act. Charles W. Morris (ed.) Chicago, University of Chicago Press, 1938. $696 \mathrm{p}$.

68. Meissner, W.W. Thinking about the family - psychiatric aspects。 Family Process 3:1-40. 1964.

69. Mittleman, Bela. Analysis of reciprocal neurotic patterns in family relationships. In: Victor $W$. Eisenstein's Neurotic interaction in marriage. New York, Basic Books, 1956. p. 81-100.

70. Miyamoto, S. Frank and Sanford M. Dornbusch. A test of interactionist hypotheses of selfconception. American Journal of Sociology $61: 399-403.1956$.

71. MontaIvo, Fr。F゙。 Homeostasis in functional and dysfunctional family systems. Based on a paper submitted for a Seminar on Family Group Treatment, University of California, Berkeley: Homeostasis and general systems -- their relevance to famjly theory and treatment。 July 1963。 p.113-125.

72. Mowrer, Ernest R, and Harriet Mowrer. The social psychology of marriage. American Sociological Review 16:27-36。1961。

73. Murrell, Stanley $A_{\text {. }}$ and James $G$. Stachowiak. The family group: development, structure, and therapy. Journal of Marriage and the Family 27:13-18. 1965.

74. Murstein, Bernard I. The complementarity need hypothesis in newlyweds and middle-aged couples. Journal of Abnominal and Social Psychology 63:194-197. 1961. 
75. Parsons, Talcott. The social system. Glencoe, Free Press, 1951. 575 p.

76. Parsons, Talcott and Robert F. Bales. Family socialization and interaction process. Glencoe, Free Press, 1955. $422 \mathrm{p}$.

77. Parsons, Talcott, Robert F. Bales and Edward A. Shils. Working papers in the theory of action. Glencoe, Free Press, 1953. 269 p.

78. Pincus, Iily (ed.) Marriage: studies in emotional conflict and growth. Iondon, Methuen, 1960. 259 p.

79. Plato. Dialogues, $\operatorname{Tr}$ by B. Jowett. vol. I New York, Random House, 1937. 879 p.

80. Polansky, Norman A. The concept of verbal accessibility. Smith College Studies in Social Work 36:1-48. October 1965.

81. Rapoport, Rhona and Robert Rapoport. Work and family in contemporary society. American Sociological Review 30:381-394. 1965.

82. Rich, Margaret E. A belief in people; a history of social work. New York, Family Service Association. of America, 1956, $190 \mathrm{p}$.

83. Rollins, Boyd Carter. Values, consensus and cohesion in the husband-wife dyad. (Abstracted in Dissertation Abstracts 22:4112. May 1962).

84. Rosow, Irving. Issues in the concept of needcomplementarity. Sociometry 20:216-233. 1957.

85. Ruesch, Jurgan and Gregory Bateson. Communication: the social matrix of psychiatry. New York, Norton, 1951。314 p。

86. Ruesch, Jurgan and Weldon Kees. Nonverbal communjcation: notes on the visual perceptions of human relations. Berkeley, University of California Press, 1956. $205 \mathrm{p}$.

87. Sampson, Edward E. (ed.) Approaches, contexts and problems of social psychology; a book of regdings. New Jersey, Prentice-Ha11, 1964. 576 p. 
88. Sarbin, Theodore R. Role theory. In: Gardiner Lindzey"s Handbook of social peychology. vol. I. Cambridge, Addison-Wesley, 1954. p.223-250.

89. Sarwer-Foner, GoJ. Patterns of marjtal relationships. American Journal of Psychotherapy 17:3]-4.4. 1963.

90. Satir, Virginia Conjoint family therapy; a guide to theory and technique. Palo Alto, Science and Beharior Books, 1964. 196 p.

91. Schachter, Stanley. Deviation, rejection and communication. In: Lorwin Cartwright and Alvin Zander's Group dynamics, research and theory. New York, Harper-Row, 1960. p. 260-285.

92. Schramm, Wilbur (ed.) Communication research in the United States for the science of human communication. New York, Basic Books, 1963. 158 p.

93. Selltiz, Claire et al. Research methods in social relations. New York, Henry Holt, 1960. 622 p.

94. Shibutani, Tamotsu. Society and personality. New Jersey, Prentice-Ha.l , 1.961. 630 p。

95. Simmel, Georg.. The sociology of Georg Simmel. Tr. by Kurt Ho Wolff (ed。) Glencoe, Free Press, 1.950. 445 p.

96. Spiegel, John $P$. and Norman $W$. Bell. The family of the psychiatric patient. In: Silvano Arieti"s American handbook of psychiatry. vol. I. New York, Basic Books, 1959. p. 114-149.

97. Strodtbeck, Fred I. Husband-wife interaction over revealed differences. American Sociological Review $16: 468-473$. 1951.

98. Stryker, Sheldon. Symbolic interaction as an approach to family research. Marriage and Family Iiving $21: 111-119.1959$.

99. Tarde, Gabriel de. The laws of imitation. Tr. from the 2d French edition by Elsie Clews Parsons. New York, Henry Holt, 1903。 404 p.

100. Thayer, Tuee 0 . On theory-bulding in communication. some conceptual problems. Tournal of Communication $13: 217-235.1963$. 
101. Titchener, James I. et al. Family transactions and derivation of individuality. Family Process $2: 95-120.1 .963$.

1.02. Vygotsky, I.S. Thought and language. Tr. by Eugenia Haufman and Gertrude Vaker (eds.) Cambridge, M.I.T. Press, 1962. 168 p.

103. Weiss, Viola and R.R. Monroe. A framework for understanding dynamics: part I. Social Casework 40:3-9. 1959.

104... Winch, Robert F. The modern family. New Yorix, Henry Holt, 1952. $522 \mathrm{p}$.

105.

The theory of complementary needs in mate selection: a test of one kind of complementariness. American Sociological Review $20: 52-56.1955$

106. Winch, Robert F., Thomas Kt,sanes and Virginia Ktsanes. The theory of complementary needs in mate selection: an analytic and descriptive study. American Sociological Review 19:241-249. 1954.

107. Witmer, Helen Leland and Ruth Kotinsky (eds.) Personality in the making. New York, Harper, 1952. $454 \mathrm{p}$.

108. Wolfe, Donald M. and J. Diedrick Snoek. A study of tensions and adjustments under role conflict. In: Warren G. Bennis' et al. Interpersonal. dynamics: essays and readings on human interaction. Illinois, Dorsey Press, 1964. p. $431-439$.

109. Yelaja, Shanker A. The concept of authority and its use in child protective service. Child Welfare 44:514-524. 1965.

110. Zetterberg, Hans $I$. On theory and verification in sociology. New Jersey, Bedminster Press, 1963. $84 \mathrm{p}$.

111. Zimmerman, C.C. and M.E. Frampton. Family and society: a study of the sociology of reconstruction. New York, Van Nostrand, 1935. $611 \mathrm{p}$. 


\section{GIOSSARY}

The act - behavior by an organism which stems from an impulse requiring some adjustment to relevant objects in an external world.

Adaptation - reciprocal relationship between the organism and its environment:

Assumptions - judgments accepted as true without demonstrated proof.

Cohesiveness - the total field of forces which act on members to remain in the group.

Communication - all those processes by which people influence one another. Fox this paper: when $A$. makes a statement to $B$, the process produces change in $A$ and in $B$. A single act as a part of the process of interaction.

Concept - an abstraction of characteristics common to a group of objects or events.

Congruence - agreement.

Double bind - "The 'double bind' is a communication mode in which contradictory injunctions are expressed on different levels of abstraction; and where something is shifted from one level of abstraction to another in order to conceal or disguise its meaning" (Dorothy Jones, 1964, p. 323).

Dysfunction - ineffective means of problem solving.

Emergence - phenomenon that cannot be predicted from its constituent parts.

Equilibrium - a state of balance produced by the counteraction of two or more forces.

Family - "A unity of interacting persons" (Burgess, 1926, p. 5). 
Feedback - action by an individual which is recognized by another individual as a response to his own previous action.

Homeostasis - "Those intricate processes occurring within a family which are made up of patterned interrelationships among family members and result in maintaining the conditions for family integration that were previously arrived at by members of the family" (Montalvo, 1963, p. 114).

I - George Herbert Mead's concept of the original, initiating quality of the personality.

Influence - art or power of producing an effect without apparent force or direct authority.

Interaction - a reciprocal relationship in which each person may produce effects on the other.

Interaction, Expressive - actions reuniting family members including expressions of affection for each other, warmth, and a symbolization of common membership through supportive, accepting behavior.

Interaction, Instrumental - actions focused on achievement of tasks often dispersing family members for such achievement.

Interaction, Symbolic - symbols in communication which are significant or mutually meaningful for each person involved.

Interpersonal Competence - acquired ability to interact with other people effectively according to some criterion which is not necessarily satisfaction of the individuals. Principal components: health, intelligence, empathy, autonomy, judgment, creativity.

Language - human speech or the written symbols for speech.

Marriage - "... a process of interaction between two people, a man and a woman, who have fulfilled certain legal requirements and have gone through a wedding ceremony or are otherwise accepted as married by the law. . . We do not refer to the pair of persons involved by marriage but to the set of their acts which are mutually dependent upon each other, i.e., which constitutes interaction" (Karlisson, 1963, p. 12). 
Me - George Herbert Mead's concept of objective self or the organized attitudes of others within the personality.

Mind - ". . organized totality or system of all mental processes or psychic activities, u.sually of an individual organism . ." (English and English, 1.958, p. 323).

Other, Generalized - a reference group whose responses an actor must be able to anticipate in order that he may know how to behave. "To take the role of the generalized other is to see one's be-: havior as taking place in the context of a defined system of related roles". (Stryker, 1959, p. 115).

Other, Significant - person an individual perceives as having value or influence.

Pattern - "A sequence of actions involving two or more family members which i.s repetitive, has some degree of automaticity, and is employed as part of the adaptive function of the family system" (Titchener et al, 1963, p, 113).

Perception - awareness or the process of becoming aware by means of sensory processes and under the influence of set and of prior experiences.

Personality - the developed psychological organization of the individual that includes his attitudes, ideas, and habits.

Position - the location of an actor or class of actors in a system of social relationships.

Power - ability of an individual to get what he wants without having to modify his own conduct.

Role - the part played by an actor; behavior that is characteristic and expected.

Role Conflict - exposure of the actor to conflicting sets of legitimized expectations such that complete fulfillment of both is realistically impossible.

Role Expectation - characteristics that determine whether a person will be satisfied with a role or not. 
Role Taking - anticipation of the response of others involved in the same social. act.

Self - that which arises as an object within the personality. Self is developed in the give and take of social relations.

Self-consciousness - the activity of oneself from the standpoint of others.

Social Psychology - that branch of psychology which studies the phenomena of social behavior.

Socialization - process by which the individual learns how to view and evaluate his behavior and act with reference to himself as well as others.

Symbol - an object used to represent something else.

Theory - an internally consistent body of verified hypotheses when verification is provisional rather than absolute.

Thinking - the internalized manipulation of language symbols.

Transaction - a two-phase, cyclical exchange between two individuals in which there is constant feedback which is largely self-regulating and self-correcting and which modifies the subsequent response of each.

Volition - selection among alternatives symbolically present. 